\title{
COMPASS - COMparative Particle formation in the Atmosphere using portable Simulation chamber Study techniques
}

\author{
B. Bonn ${ }^{1, *}$, S. Sun ${ }^{1, * *}$, W. Haunold ${ }^{1}$, R. Sitals ${ }^{1}$, E. van Beesel ${ }^{1}$, L. dos Santos ${ }^{1}$, B. Nillius ${ }^{1}$, and S. Jacobi ${ }^{2}$ \\ ${ }^{1}$ Institute for Atmospheric and Environmental Sciences, J.W. Goethe University, Altenhöferallee 1, \\ 60438 Frankfurt am Main, Germany \\ ${ }^{2}$ Hessian Agency for the Environment and Geology (HLUG), Rheingaustrasse 186, 65203 Wiesbaden, Germany \\ *now at: Institute for Advanced Sustainable Studies, Berliner Straße 130, 14467 Potsdam, Germany \\ ** now at: Department of Biogeochemistry, Max Planck Institute for Chemistry, Hahn-Meitner-Weg 1, \\ 55028 Mainz, Germany
}

Correspondence to: B. Bonn (boris.bonn@ iass-potsdam.de)

Received: 5 June 2013 - Published in Atmos. Meas. Tech. Discuss.: 27 June 2013

Revised: 20 September 2013 - Accepted: 4 November 2013 - Published: 9 December 2013

\begin{abstract}
In this study we report the set-up of a novel twin chamber technique that uses the comparative method and establishes an appropriate connection of atmospheric and laboratory methods to broaden the tools for investigations. It is designed to study the impact of certain parameters and gases on ambient processes, such as particle formation online, and can be applied in a large variety of conditions. The characterisation of both chambers proved that both chambers operate identically, with a residence time $x_{T}($ COMPASS1) $=26.5 \pm$ $0.3 \mathrm{~min}$ and $x_{T}$ (COMPASS2) $=26.6 \pm 0.4 \mathrm{~min}$, at a typical flow rate of $15 \mathrm{~L} \mathrm{~min}^{-1}$ and a gas leak rate of $(1.6 \pm$ $0.8) \times 10^{-5} \mathrm{~s}^{-1}$. Particle loss rates were found to be larger (due to the particles' stickiness to the chamber walls), with an extrapolated maximum of $1.8 \times 10^{-3} \mathrm{~s}^{-1}$ at $1 \mathrm{~nm}$, i.e. a hundredfold of the gas leak rate. This latter value is associated with sticky non-volatile gaseous compounds, too. Comparison measurement showed no significant differences. Therefore operation under atmospheric conditions is trustworthy. To indicate the applicability and the benefit of the system, a set of experiments was conducted under different conditions, i.e. urban and remote, enhanced ozone and terpenes as well as reduced sunlight. In order to do so, an ozone lamp was applied to enhance ozone in one of two chambers; the measurement chamber was protected from radiation by a first-aid cover and volatile organic compounds (VOCs) were added using a small additional flow and a temperaturecontrolled oven. During the elevated ozone period, ambient particle number and volume increased substantially at urban
\end{abstract}

and remote conditions, but by a different intensity. Protection of solar radiation displayed a clear negative effect on particle number, while terpene addition did cause a distinct daily pattern. E.g. adding $\beta$ pinene particle number concentration rose by $13 \%$ maximum at noontime, while no significant effect was observable during darkness. Therefore, the system is a useful tool for investigating local precursors and the details of ambient particle formation at surface locations as well as potential future feedback processes.

\section{Introduction}

The change of climate conditions on regional and global scale has been reported and is established (IPCC report, Solomon et al., 2007). In this context certain aspects such as temperature, radiation budgets, volatile organic compounds and ozone will change differently on different scales. In order to understand and approximate certain effects and their feedback on climate in an appropriate way, novel tools are needed to link laboratory-based results with ambient observations. This includes detailed laboratory techniques and the extrapolation of knowledge to ambient conditions in order to understand ambient observations.

With any of the mentioned approaches, observation is controlled by the applied approach techniques, which cause significant benefits and problems (see Table 1): e.g. basic challenges (disadvantages) of all simulation chamber approaches 
Table 1. List of pros and cons for the present set-up (COMPASS) compared to simulation chamber studies and atmospheric measurements.

\begin{tabular}{|c|c|c|c|}
\hline Aspect & $\begin{array}{l}\text { Simulation } \\
\text { chambers }\end{array}$ & COMPASS & Ambient meas. \\
\hline $\begin{array}{l}\text { Controlled conditions } \\
\text { (gases, } T, \mathrm{RH}, \text { particles and } \\
\text { composition) }\end{array}$ & yes (pro) & $\begin{array}{l}\text { partly yes (modified param- } \\
\text { eter(s), basic conditions, } \\
\text { pro), partly no (several un- } \\
\text { knowns, con) }\end{array}$ & no (con) \\
\hline $\begin{array}{l}\text { Atmospheric mixing } \\
\text { (transport, dilution) }\end{array}$ & no (con) & $\begin{array}{l}\text { a priori not after entering } \\
\text { the tubes }\end{array}$ & yes (pro) \\
\hline $\begin{array}{l}\text { Acquisition of knowledge } \\
\text { (formation processes, } \\
\text { interaction, heterogeneous } \\
\text { chemistry) }\end{array}$ & $\begin{array}{l}\text { condition specific but dif- } \\
\text { ficulties in extrapolating to } \\
\text { ambient conditions (pros } \\
\text { and cons) }\end{array}$ & & $\begin{array}{l}\text { interdisciplinary approach } \\
\text { needed, huge data analysis, } \\
\text { difficulties in separation of } \\
\text { effects }\end{array}$ \\
\hline $\begin{array}{l}\text { Applicability to } \\
\text { atmospheric conditions }\end{array}$ & $\begin{array}{l}\text { usually not directly, } \\
\text { extrapolation needed }\end{array}$ & $\begin{array}{l}\text { yes, chosen condition } \\
\text { specific (pro) }\end{array}$ & certainly (pro) \\
\hline Particle loss & $\begin{array}{l}\text { Yes (con), the longer the } \\
\text { worse }\end{array}$ & $\begin{array}{l}\text { Yes (pro), balanced by } \\
\text { using two chambers }\end{array}$ & no (pro) \\
\hline Sampling flow limitations & yes (con) & yes (con) & no (pro) \\
\hline $\begin{array}{l}\text { Comparable to similar } \\
\text { conditions for effect studies }\end{array}$ & yes (pro) & yes (pro) & $\begin{array}{l}\text { hardly because of several } \\
\text { unknowns (con) }\end{array}$ \\
\hline Box model studies & possible (pro) & possible (pro) & hardly poss. (con) \\
\hline
\end{tabular}

are wall losses, limited amount of mixture ingredients, moderate path lengths for spectroscopy, enhanced concentrations and - depending on the set-up - either a limited amount of reaction time (flow chambers) or of volume (static chambers). Otherwise, conditions are well defined and mechanistic studies of e.g. kinetics are possible. This facilitates the application of a box model to simulate observed processes in a very detailed way. The conditions are rather different for ambient studies; important compound concentrations sometimes hardly exceed the detection limit, a notable heterogeneity of the site is present with changes in the local compound distribution and the time resolution actually depends on the instruments used. Usually no past condition can be changed or investigated again, that means the benefit of laboratory techniques to repeat the experiment for different conditions is not available. A summary of all these aspects is given in Table 1 .

Both approaches include strong benefits and some weaknesses: the smog-chamber-based one investigates processes under well quantified conditions such as temperature, humidity, radiation and gaseous concentrations. The conditions can be chosen in the way that best suits the observational techniques. Because of volume limitations (static chambers) or time limitations (flow chambers) this approach is limited in process time. The smog-chamber approach can be divided into subgroups, i.e. set-ups exploring definite mixtures in a static or dynamic vessel with an artificial light source that is supposed to be similar to the ambient one. Examples are the sphere reactor at Max Planck Institute for Chemistry (Neeb et al., 1995), the Paul-Scherer-Institute- Simulation Chamber for Atmospheric Chemistry (PSI-SCAC) chamber at the Paul Scherer Institute (CH) (Paulsen et al., 2005), the TPOT chamber at Toronto University (CND) (Slowik et al., 2012), the Potential Aerosol Mass reactor (PAM) at Pennsylvania State University (USA) (Kang et al., 2007) and the CESAR chamber at Creteil (F) (Wang et al., 2011) Other techniques such as the large simulation chambers at Valencia (ES) (EUropean PHOtoREactor, EUPHORE, Becker, 1996), at Juelich (D) (Simulation Atmospheric PHotochemistry In a large REactor, SAPHIRE, Karl et al., 2004) and at the California Institute of Technology (USA) (Caltech chamber, Kroll and Seinfeld, 2005) use certain air mixtures and expose them to ambient light conditions to simulate an accurate daily pattern and behaviour. Some of those techniques use initially ambient air in order to process it further on and to figure out potential changes in properties - for instance, of ambient aerosols over time (ageing). Among the benefits of laboratory studies, the following aspects can be named as examples: controlled conditions, investigations under suitable conditions, application of measurement techniques under homogeneous conditions and facilitation of a detailed process based simulation because of the fixation of well-known boundary conditions (see Table 1). The disadvantages include primarily the elevated concentration used for precursor gases, the reactor surface losses for sticky compounds and leak rates and the limitation in process evolution either in time or in volume. Ambient measurements allow the determination of a wide 
range of different conditions and their annual patterns. These include, in general, micrometeorology and gas- and aerosolphase measurements. Examples of this kind of set-up can be found e.g. at the SMEAR research stations in Hyytiälä (FIN) (Rannik, 1998) or at the Blodgett forest (USA) (Holzinger et al., 2005). Seasonal impacts of parameters on specific processes and changes over time have been derived from the observations made (Hyvönen et al., 2005; Lyubovtseva et al., 2005). Missing aspects can be revealed as well as quantified. Examples include missing volatile organic compound emissions (Goldstein and Galbally, 2007), missing OH reactivity (Lelieveld et al., 2008; Lelieveld, 2010; Nölscher et al., 2012) and the lack in process understanding of ambient new aerosol particle formation (Kulmala et al., 2013). However, the reduced concentration of parameters in the ambient conditions competes with the detection limits of the applied instruments, resulting in a gap of knowledge.

However, due to the spot-like measurements that are affected by transport, local sources and sinks and the time resolution of instruments, separation of individual aspects is challenging in the highly nested atmospheric system. We aim to address this gap with our new comparative and portable twin flow chamber COMPASS, which facilitates the usage of laboratory tools in a certain time frame under ambient conditions. The flow-chamber approach allows the investigation of a process in a certain time scale for ambient and modified conditions. Since the set-up is portable, different locations and conditions can be compared with respect to atmospheric conditions and the extrapolation of laboratory-based results can be checked. Based on this approach, a future increase in temperature or of natural gas concentrations, for example, could be investigated, as well as the impact of certain anthropogenically enhanced species. In this study, the construction, characterisation and exemplary application for a well-known ambient problem is explained.

This well-known problem concerns the ambient new aerosol particle formation processes from gaseous precursors, which have been observed all around the globe (Kulmala et al., 2004c) and which have been studied for more than a century. A wide range of theories have been developed as explanations; these include primarily sulfuric-acidrelated mechanisms such as binary and ternary nucleation (Kulmala et al., 2004b). These are expected to take place in the free troposphere and in the vicinity of significant ammonia sources, such as agriculture and farming (Korhonen et al., 1999; Spracklen et al., 2010). Others, like the ion-induced nucleation (Hirsikko et al., 2011; Kirkby et al., 2011) or the iodine oxide related oligomerisation (Burkholder et al., 2004), have been demonstrated to be relevant for the upper troposphere or the coastal zones, whereas algae emissions of diiodomethane $\left(\mathrm{CH}_{2} \mathrm{I}_{2}\right)$ occur at draught stress conditions (O'Dowd and Hoffmann, 2005). In the case of coastal new particle formation, the emitted volatile organic compounds (VOCs) subsequently react with ambient ozone and start the process of new aerosol particle production. Besides the mentioned ones, several further theories have been postulated (Ryding et al., 2012; Bonn et al., 2002; Bonn and Moortgat, 2003; Bonn et al., 2008) but could not be proven by aerosol mass spectrometry techniques (Jimenez et al., 2009) as the corresponding particular mass is too small and particles undergo chemical transformation during accumulation. This problem is severe, since only very tiny amounts (perhaps less than a $\mathrm{ppt}_{\mathrm{v}}$ ) of a compound are required to create a new phase, if the compound of interest has the right physic-chemical properties, i.e. low volatility, notable interaction with other species or a high chemical reactivity (Bonn et al., 2007, 2013). Nevertheless, once the new particles are formed, a significant fraction grows beyond the size at which it can act as cloud condensation nuclei (CCN) and alter the physical size distribution of cloud droplets. This has a remarkable impact on the radiation budget in the climate system (Kulmala et al., 2004a; Merikanto et al., 2009) and provides the key uncertainty in predicting climate feedbacks and processes. Therefore, a novel technique for investigating these processes is needed.

So far most of the so-called nucleation studies have been performed under controlled laboratory conditions, sometimes with enhanced precursor concentrations to speed up the formation and early growth. The concluding results are then used to interpret ambient observations and processes (Bonn et al., 2009), an aspect that is subject to criticism. In this study, we report a novel technique that uses the comparative method and provides a mixture of atmospheric and laboratory methods. It is designed to study the impact of certain parameters and gases online and can be applied in a large variety of conditions.

\section{Material and methods}

\subsection{Construction}

The construction of two identical twin chambers aims to measure atmospheric situations under two sets of conditions, identical except for one parameter, to investigate the impact of the parameters on the process observed (Sun, 2013). It shall allow a notable residence time to investigate slowly occurring processes and aims to reduce dry wall loss to a minimum and the surface to be chemically inert. Thus both twin chambers shall alter ambient conditions to a minimum level.

The surface material is made of ethylene tetrafluoroethylene (ETFE, Texlon $\mathrm{GmbH}$ ). It has a high level of transparency in the UV region (95\%) and in the visible range $(83.6 \%)$ (Table 2) i.e. higher than glass. It is inert, selfcleaning and very resistant to chemical reactive substances like ozone. It is temperature-resistant up to 150 degrees Celsius. The material is weatherproof (wind, temperature and rain) and the selected foil has a thickness of $25 \mu \mathrm{m}$.

The scaffold of the twin chambers is made of stainless steel with a total height of $3 \mathrm{~m}$, which stabilises the chamber 


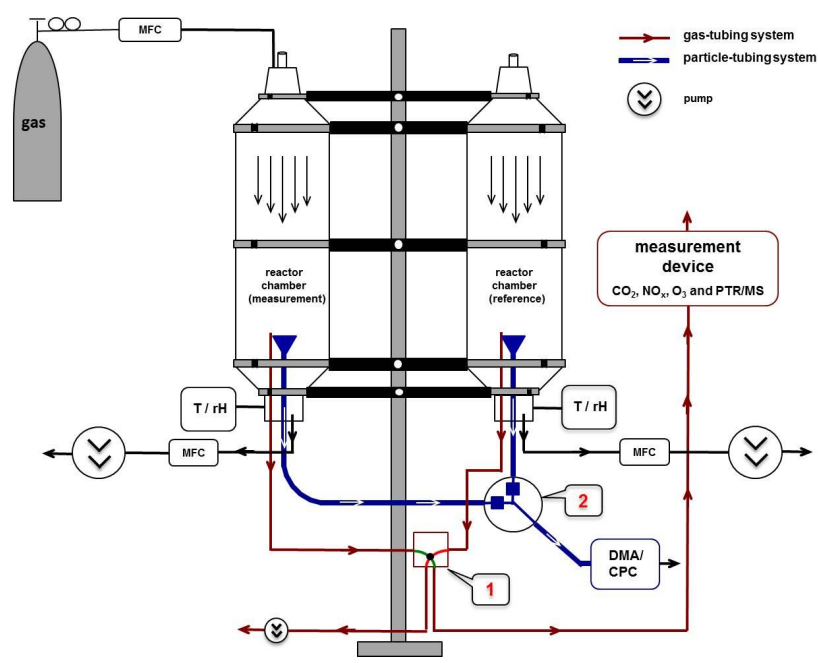

Fig. 1. Flow chart of the COMPASS system. Valve system 1 (magnetic valve) and 2 (Grotec valve) are used for the periodic change of gas and particle sampling between modification and reference chamber.

towers on the right and left sides of the scaffold with several carrier rings (Fig. 1). The foothold material is formed as two rings on each chamber, i.e. one on the outside and one inside. Each outer (carrier) ring is fixed on the scaffold and its diameter can be narrowed by a screw to fix the foil between the outer and inner ring. The foil is welded vertically to a cylinder. This cylindrical main section of each chamber has a total height of $1.8 \mathrm{~m}$ and a diameter of $50 \mathrm{~cm}$. At the inlet and outlet region of the chamber, the cylindrical form is reduced concentrically. Above and below the main section, the diameter of the cylinder reduces from 50 to $15 \mathrm{~cm}$ in both, i.e. the upper and lower, parts. The reduction of the inlet diameter aims to focus the direction of the inlet stream and to minimise the influence of turbulence. Mounted at the top is an inlet tube consisting of acrylic glass, which is connected to a cover plate with a flange. Finally, a flexible aluminium tube bent towards the ground is fixed at each of the chambers to protect them from rain.

In the following, one of the chambers is used as a reference (COMPASS1) while the second one (COMPASS2) is modified as desired. Therefore COMPASS2 has an additional glass inlet for adding gases.

The chamber outlet is situated in the centre of the flow tube at the lowest part of the chamber. Two different outlet lines for gases and aerosol particles are chosen to prevent destruction of chemicals in the conducting tubes for the aerosol particle analysis. The flow dynamics are kept laminar with a Reynolds number (Re) of 420 and can be expected as simulated using the FLUENT 6.1 software (Fig. 2) for $15 \mathrm{~L} \mathrm{~min}^{-1}$. The total flow rate in each chamber is controlled by mass flow controllers and electrical pumps. To allow sampling with a minimum of instrumentation, both

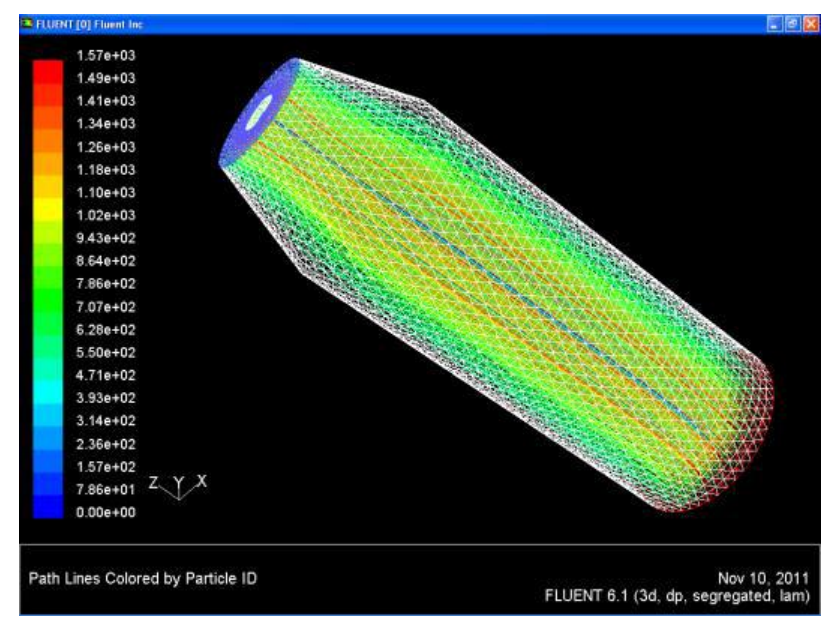

Fig. 2. Flow simulation for the COMPASS system using the FLUENT 6.1 software.

chamber outlets (COMPASS1 and 2) for gases and particles are connected to electrical switches (gases: magnetic valve, Bückert; particles: OSE-KKP, Grotec) controlled by a Labview card (National Instruments) and program that switches in $5 \mathrm{~min}$ intervals between both chambers ( $\Delta t=10 \mathrm{~min})$. To guarantee that the flow is stable during the changing time of the magnetic valve, there is a second magnetic valve, which is coupled with the first one. In this way an additional pump with the same flow rate as the gas measurement device can stabilise the flow of that chamber, which is current uncoupled from the gas measurement.

\subsection{Instrumentation for measurements}

\subsubsection{Gaseous and meteorological measurements}

Temperature and relative humidity are measured by $\mathrm{Hy}$ grosens sensors (Model: HYTE-ANA-10V, Hygrosens) at the end of each chamber in $5 \mathrm{~s}$ intervals. A comparison of the two sensors at controlled laboratory conditions yielded no significant difference outside the measurement uncertainty. Note that both sensors are not protected from sunlight in order to modify flow conditions only to a minimum extent. Thus temperatures higher than the ambient ones are to be expected. The chambers are constructed identically in order to enable one to compare the data afterward on a relative scale. Ozone was detected using the Horiba APOA-350E instrument alternatively in COMPASS1 and 2. Its sampling flow was set to $1 \mathrm{~L} \mathrm{~min}^{-1}$, and the measurement range was chosen to fit best to the range of expected values. For volatile organic compounds, a high-sensitivity proton transfer reaction mass spectrometer (HS-PTR-MS, Ionicon, Innsbruck, Austria) was applied and was operated in the same manner as the ozone sample. Important masses were selected by running a mass scan at the start of each set-up. Chosen masses were either significantly different in both chamber samples 
Table 2. Transparency measurements concerning the chamber wall material of ETFE foil obtained for a thickness of $200 \mu \mathrm{m}$ (Asahi Glass Company Ltd.).

\begin{tabular}{ll}
\hline Spectral range & Percentage of light passing \\
\hline $300-380 \mathrm{~nm}$ (UV) & $90.5 \%$ \\
$380-780 \mathrm{~nm}$ (visible) & $83.5 \%$ \\
$300-2100 \mathrm{~nm}$ (sunlight) & $91.9 \%$ \\
\hline
\end{tabular}

or were selected because of significant local sources. The sampling time for the individual masses was adapted to the present mixing ratio range, i.e. the smaller the concentration the larger the measurement time resulting in a total time resolution between 32 and $37.4 \mathrm{~s}$. For more details the reader is referred to Bourtsoukidis et al. (2012).

\subsubsection{Particle phase measurements}

In order to physically characterise the ambient particle number and mass concentration, two different set-ups were applied: (a) for quantification of the total aerosol number concentration, a buthanol-based condensation particle counter (CPC, TSI 3025A, TSI Inc., US) with a lower cut-off size of $2.7 \mathrm{~nm}$ in diameter was used and averaged for $30 \mathrm{~s}$ intervals. Flows were calibrated before application and regularly afterwards. (b) To measure the particle volume and mass as well, the system was extended to a scanning mobility particle sizer (SMPS, TSI 3936, TSI Inc., US). This instrument was configured as follows: sample flow $=1.5 \mathrm{~L} \mathrm{~min}^{-1}$ (high flow), sheath flow $=6.0 \mathrm{~L} \mathrm{~min}^{-1}$, particle density assumed to be $1.2 \mathrm{~g} \mathrm{~cm}^{-3}$, and two scans per sample with $120 \mathrm{~s}$ upscan and $15 \mathrm{~s}$ downscan. These times result in a total sampling time of the SMPS per sample of $4 \mathrm{~min} 30 \mathrm{~s}$. The remaining $30 \mathrm{~s}$ for a total of $5 \mathrm{~min}$ interval the SMPS was set to pause in order to prevent measurements during the switch from one to the other chamber.

To maintain the total flow rates in both chambers identical a set of 4 flow controllers was used. Since gas- and particlephase measurements took place in alternating chambers with a match of the total flow rates of gases and of aerosol particles $\left(1.5 \mathrm{~L} \mathrm{~min}^{-1}\right)$ the corresponding residual flows were selected accordingly.

\subsubsection{Data analysis and intercomparison}

Since the focus is on a relative comparison of the two chamber results, the measurements for each parameter were divided into data sets for the individual chambers using the recorded valve switching times and the MATLAB software (The MathWorks, Inc.). Subsequently all values between $30 \mathrm{~s}$ and $4.5 \mathrm{~min}$ after switching were averaged. The mean values were used to calculate the ratio of value (COMPASS2)/value(COMPASS1) using the COMPASS2 interval following the COMPASS1 interval, which is the first to be measured when starting the magnetic and the GROTEC valves. This assumes that no significant change occurs in any chamber in smaller time steps than $5 \mathrm{~min}$.

\section{Results}

\subsection{Determination of chamber residence time}

Due to the unreactive properties of $\mathrm{CO}_{2}$, this gas was used as a trace gas to determinate the residence time inside the chamber. The gas was added into the inlet region of the chamber from a specific time on. At the outlet region the timedependent rise of the $\mathrm{CO}_{2}$ mixing ratio was measured by a $\mathrm{CO}_{2}$-measurement device (BIOS $\left.{ }^{\circledR} 100\right)$. The $50 \%$ change time between the initial and the final $\mathrm{CO}_{2}$-mixing value was taken as the residence time for gases and aerosol particles in the central area of the chambers covered by the hoppershaped outlet. An exponential fit of the normalised $\mathrm{CO}_{2}$ data vs. time was added to calculate the residence time with following function:

$$
\begin{aligned}
& y=A_{1} \exp \left(-\frac{x}{t_{1}}\right)+y_{0}, \\
& \rightarrow x_{\tau}=-\ln \left[\frac{y-y_{0}}{A_{1}}\right] \cdot t_{1} .
\end{aligned}
$$

$x$ represents the measured time, $y$ the normalised $\mathrm{CO}_{2}$ mixing ratio, $y_{0}$ the normalised initial $\mathrm{CO}_{2}$ mixing ratio and $A_{1}$ and $t_{1}$ are fitting parameters. The residence time $x_{\tau}$ can be calculated by Eq. (2) assuming $y=0.5$ and $y_{0}=0$ by application of the fitting values from Eq. (1) (Fig. 3).

The derived residence time, $x_{\tau}$, was found to change between 22 and $36 \mathrm{~min}$ as flows varied between 10 and $20 \mathrm{~L} \mathrm{~min}^{-1}$ (Table 3). In this context the value at $10 \mathrm{~L} \mathrm{~min}^{-1}$ (COMPASS1) was excluded from further analysis because of the heat exhaust of an oven close by that was turned on during this particular measurement. Using all residence time values except the discarded one the relation between flow rate and mean residence time for both identical chambers becomes

$x_{\tau}=\frac{(264.0 \pm 11.7) \mathrm{L}}{\text { flow rate }}+(9.3 \pm 0.8) \mathrm{min}$.

The residence time used for ambient measurements at $15 \mathrm{~L} \mathrm{~min}^{-1}$ was derived as $(26.5 \pm 0.3) \mathrm{min}$ for the reference chamber COMPASS1 and $(26.6 \pm 0.4) \mathrm{min}$ for the measurement chamber COMPASS2. This facilitates about $30 \mathrm{~min}$ of process modification inside to study impacts by laminar flow conditions. However, the most feasible flow for experiments essentially depends on the total required analytical flow rate (ca. 1/3 of the total flow) and the competition of process time with wall losses. For our experiments a flow rate of $15 \mathrm{~L} \mathrm{~min}^{-1}$ was chosen because of a need of about $4 \mathrm{~L} \mathrm{~min}^{-1}$ for analysis. 


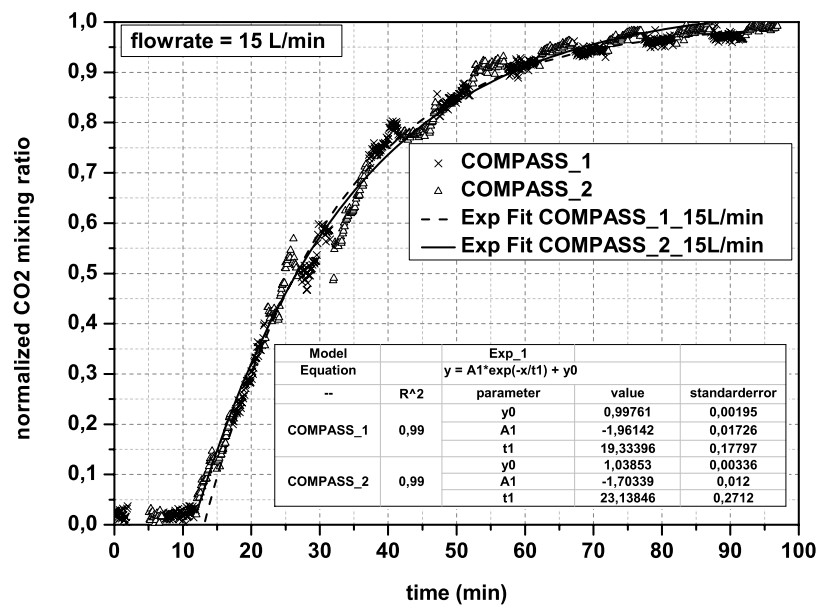

Fig. 3. Measured temporal pattern of the normalised $\mathrm{CO}_{2}$ mixing ratio at the outlet at a flow rate of $15 \mathrm{~L} \mathrm{~min}^{-1}$ at a sudden $\mathrm{CO}_{2}$ increase at the inlet. Exponential fitting of the data points for calculation of the residence time.

\subsection{Determination of the loss rate of the chambers}

\subsubsection{Gas dry-wall loss rate}

The reduction of a chemically inert trace gas between inlet and outlet is based on gaseous diffusion and dry deposition to and as well as leakage through the chamber walls (wall loss) if the trace gas is not sticky and does not get lost on aerosol surfaces. In this case an identical sampling line has been used to measure the relative reduction of the $\mathrm{CO}_{2}$ mixing ratio from the inlet to outlet. The wall leak rate of inert gases is described by the following equation (Seinfeld and Pandis, 2006):

$\operatorname{vmr}_{\mathrm{CO}_{2}}=\operatorname{vmr}_{0, \mathrm{CO}_{2}} \cdot \exp \left(-k_{\text {leak, gas }} \cdot x_{\tau}\right)$,

with $\operatorname{vmr}_{\mathrm{CO}_{2}}=\mathrm{CO}_{2}$ - volume mixing ratio at inlet; $\mathrm{vmr}_{0, \mathrm{CO}_{2}}=\mathrm{CO}_{2}$ volume mixing ratio at outlet; $k_{\text {loss,gas }}=$ dry gas-phase loss rate; $x_{\tau}=$ residence time.

Restructuring Eq. (4) the variable $k_{\text {loss }}$ results in:

$k_{\text {dep, leak }}=\ln \left(\frac{\mathrm{vmr}_{0, \mathrm{CO}_{2}}}{\mathrm{vmr}_{\mathrm{CO}_{2}}}\right) \cdot \frac{1}{x_{\tau}}$.

With this the mean $k_{\text {leak,gas }}$ was obtained as $(1.3 \pm 0.6) \times$ $10^{-5} \mathrm{~s}^{-1}$. Both chambers show identical results within the range of uncertainty, having values that are in the range of laboratory-derived values (Table 4). The total loss rate of gases includes not only leak rate, but also the rate of the dry deposition onto the walls' surface (sticking). This total loss rate was extrapolated from the particle loss rate to molecular sizes with $1 \mathrm{~nm}$ in spherical diameter (Sect. 3.2.2)

\subsubsection{Particle loss rate}

For determining the particle dry wall loss rates, the same approach as in case of the gas wall loss rate was applied for
Table 3. Calculated residence time $x_{\tau}$ and standard deviation $\sigma$ by using the measured $\mathrm{CO}_{2}$ mixing ratio for flow rates of 10,15 and $20 \mathrm{~L} \mathrm{~min}^{-1}$ between measurement and reference chamber. The additional flow rate of the $\mathrm{CO}_{2}$ was $(30 \pm 1) \mathrm{mL} \mathrm{min}^{-1}$.

\begin{tabular}{llrr}
\hline $\begin{array}{l}\text { flow } \\
\text { rate }\left(\mathrm{L} \mathrm{min}^{-1}\right)\end{array}$ & chamber & $x_{\tau}(\mathrm{min})$ & $\sigma\left(x_{\tau}\right)(\mathrm{min})$ \\
\hline 10 & COMPASS1 & 35.9 & 0.2 \\
& COMPASS2 & $38.4^{*}$ & $0.4^{*}$ \\
\hline \multirow{2}{*}{15} & COMPASS1 & 26.6 & 0.4 \\
& COMPASS2 & 26.5 & 0.3 \\
\hline 20 & COMPASS1 & 23.1 & 0.4 \\
& COMPASS2 & 22.3 & 0.4 \\
\hline
\end{tabular}

* The value was excluded from intercomparison due to external heat impact but is shown for completeness.

individual particle sizes:

$C_{\text {particle }}\left(D_{p}\right)=C_{0, \operatorname{particle}}\left(D_{p}\right) \cdot \exp \left(-k_{\text {loss,part }} \cdot x_{\tau}\right)$,

with $C_{\text {particle }}=$ particle concentration at outlet; $C_{0 \text {, particle }}=$ particle concentration at inlet (aerosol $\mathrm{dy}$ namic corrected); $k_{\text {loss, part }}=$ loss rate $\left[\mathrm{s}^{-1}\right] ; x_{\tau}=$ residence time $[\mathrm{s}]$.

And again $k_{\text {loss,part }}$ becomes

$k_{\text {dep,loss }}\left(D_{p}\right)=\ln \left(\frac{C_{0, \text { particle }}\left(D_{p}\right)}{C_{\text {particle }}\left(D_{p}\right)}\right) \cdot \frac{1}{x_{\tau}}$.

Due to the residence time of $26.6 \mathrm{~min}$ at a flow rate of $15 \mathrm{~L} \mathrm{~min}^{-1}$ inside any chamber, notable aerosol dynamics will affect particle concentrations. Those include the formation, coagulation and coalescence as well as the loss of particles and will have effects on the size distributions to be corrected for intercomparison purposes. However, since the local formation of particles still remains an aspect not fully understood and might be partially related to traffic emissions, this process is assumed to compensate for the surface losses in the smallest size range most. Because of that, particles in the size range below $50 \mathrm{~nm}$ in diameter was excluded from the fitting. Because of the relevance of aerosol dynamic contributions, the dynamical effect was calculated using an aerosol dynamics box model (Jacobson, 2005) in MATLAB 2009 (The MathWorks Inc., US). The model was initialised with the aerosol size distribution gained at the inlet from ambient air at Campus Riedberg and calculated in 1s time steps for the entire residence time in the corresponding chamber. The size distribution derived from the aerosol dynamics computations after the residence time period therefore replaces the initial particle concentration in Eq. (7) to quantify the particle deposition onto the foil surface.

Figure 4 displays the maximum of particle loss at a size range of $40 \mathrm{~nm}$ in particle diameter. The loss value is $(56 \pm$ 5) $\%$ at COMPASS 1 and $(48 \pm 5) \%$ at COMPASS2, each using ambient aerosol particles and individual measurements. 
Table 4. Calculated wall loss rate of gas with the measured $\mathrm{CO}_{2}$ mixing ratio at the inlet and outlet region of the chamber.

\begin{tabular}{lllll}
\hline Chamber & VMR (inlet) $\left(\mathrm{ppm}_{\mathrm{V}}\right)$ & VMR (outlet) $\left(\mathrm{ppm}_{\mathrm{V}}\right)$ & $k_{\text {loss,gas }}\left(\mathrm{s}^{-1}\right)$ & $\Delta k_{\text {loss,gas }}\left(\mathrm{s}^{-1}\right)$ \\
\hline COMPASS1 & $828.3 \pm 6.3$ & $815.2 \pm 3.3$ & $1.0 \times 10^{-5}$ & $5.4 \times 10^{-6}$ \\
COMPASS2 & $752.4 \pm 8.7$ & $734.1 \pm 3.2$ & $1.6 \times 10^{-5}$ & $7.8 \times 10^{-6}$ \\
\hline
\end{tabular}

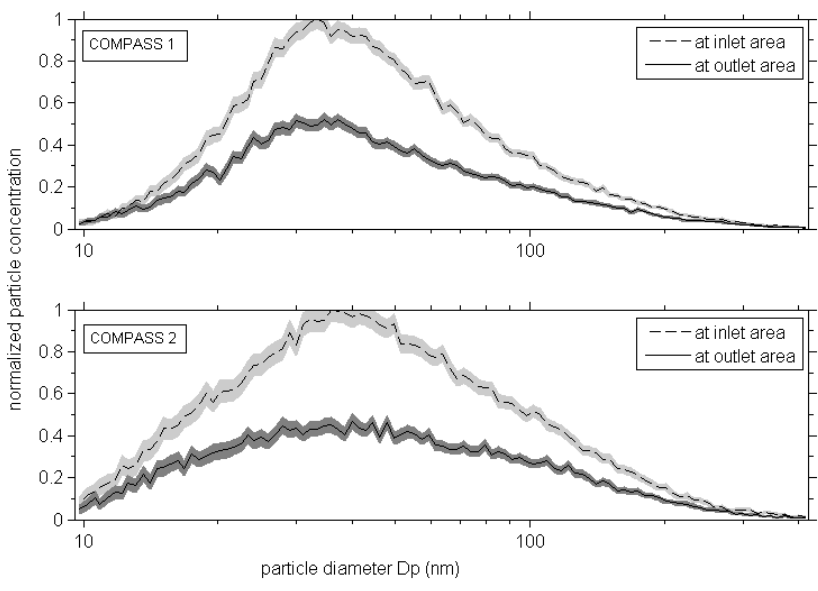

Fig. 4. Observed normalised particle number and volume concentrations at the inlet and outlet of the reference (COMPASS1) and modification chamber (COMPASS2). Normalisation was based on the maximum of COMPASS1.

The differences may partially originate from a non-stable initial aerosol, and therefore different diffusion mixing within the two chambers. However, the values of both chambers display no significant difference. The total loss rate of particles per second is provided in Fig. 5. Therefore, the fit of the mean values between 50 and $422 \mathrm{~nm}$ in particle diameter is used. Since ambient air was used for testing, smaller particles may be affected by new particle formation and subsequent growth in both chambers (see above). Therefore, the size range of potential effects is excluded from the fit.

Above, the deposition rate declines to a minimum at nearly $250 \mathrm{~nm}$. The average fit curve for both chambers is provided by

$$
\begin{aligned}
k_{\text {loss,part }} & =3.83 \times 10^{-4} \mathrm{~s}^{-1} \cdot\left(\log _{10}\left(D_{p}[\mathrm{~nm}]\right)-2.08\right)^{2} \\
& +1.83 \times 10^{-4} \mathrm{~s}^{-1} .
\end{aligned}
$$

This means that particles in such a size range pass the chamber with the smallest loss. As noted in Sect. 3.2.1, the gas loss rate was determined for a non-sticking gas (leak rate). If we extrapolate the particle-based loss rate, including sticking to the chamber wall surfaces, a loss rate of condensable gases of $k_{\text {loss, stick,gas }}=(1.84 \pm 0.01) \times 10^{-3} \mathrm{~s}^{-1}$ is obtained. Therefore sticking gases will get lost on the chamber walls about 100 times faster because of the different contributions of leak and wall deposition loss rates (compare Table 4), providing a lifetime of sticking gases in the gas phase of about

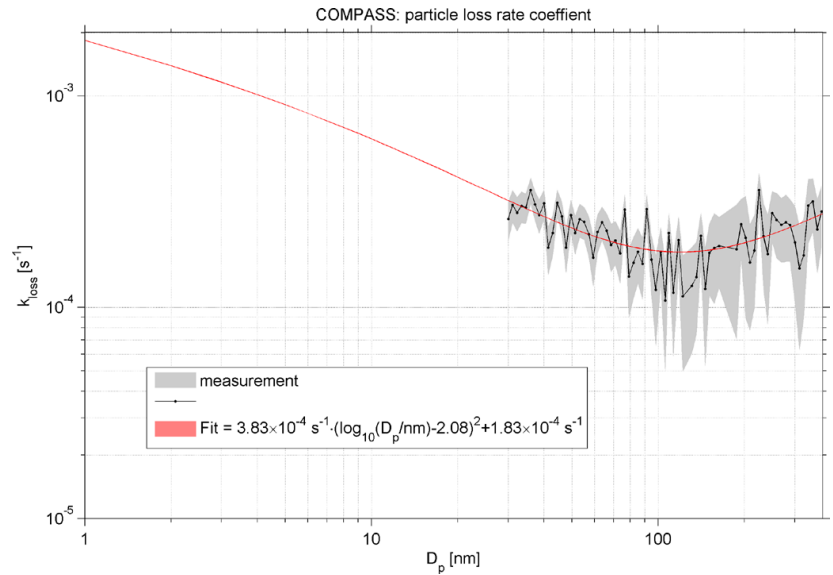

Fig. 5. Dry particle wall loss rate $k_{\text {loss, part }}$ inside the measurement and reference chambers as a function of the particle size. The uncertainty ranges are displayed by the shaded areas. The fit for the average values of both chambers between 30 and $370 \mathrm{~nm}$ is shown in red and extended to molecular sizes.

$9 \mathrm{~min}$. As the extrapolated loss rate of particles to molecular sizes results in a total loss of about $92 \%$ for sticky gases, we conclude that the use of two chambers is highly preferable for our kind of comparable effect studies.

\subsection{Intercomparison measurement period}

The intercomparison of both chambers at ambient conditions took place without any modifications in one of the chambers during September 2012 at the Riedberg campus of Frankfurt University. The results are displayed in Fig. 6. No difference is visible in the two size distribution measurements (top and centre plots), or in total particle number concentration (bottom graph), or in particle volume for more than two days at a variety of ambient conditions. Therefore the two chambers are considered to work identically.

The top and centre plots in Fig. 6 show the $\mathrm{d} N / \mathrm{d} \log \left(D_{p}\right)$ observations in COMPASS 1 and 2 during the comparison experiment between the two chambers at a particle size range from 9.65 to $422 \mathrm{~nm}$. The particle formation processes at morning and evening are obvious in the time range 269 to 270. It has the typical shape of a nucleation curve, which is also known as "banana plot". By contrast, the particle concentration at about noontime is quite less. This experiment was accomplished nearby the anthropogenic-contaminated road next to the institute. So it is rather likely that the particle 

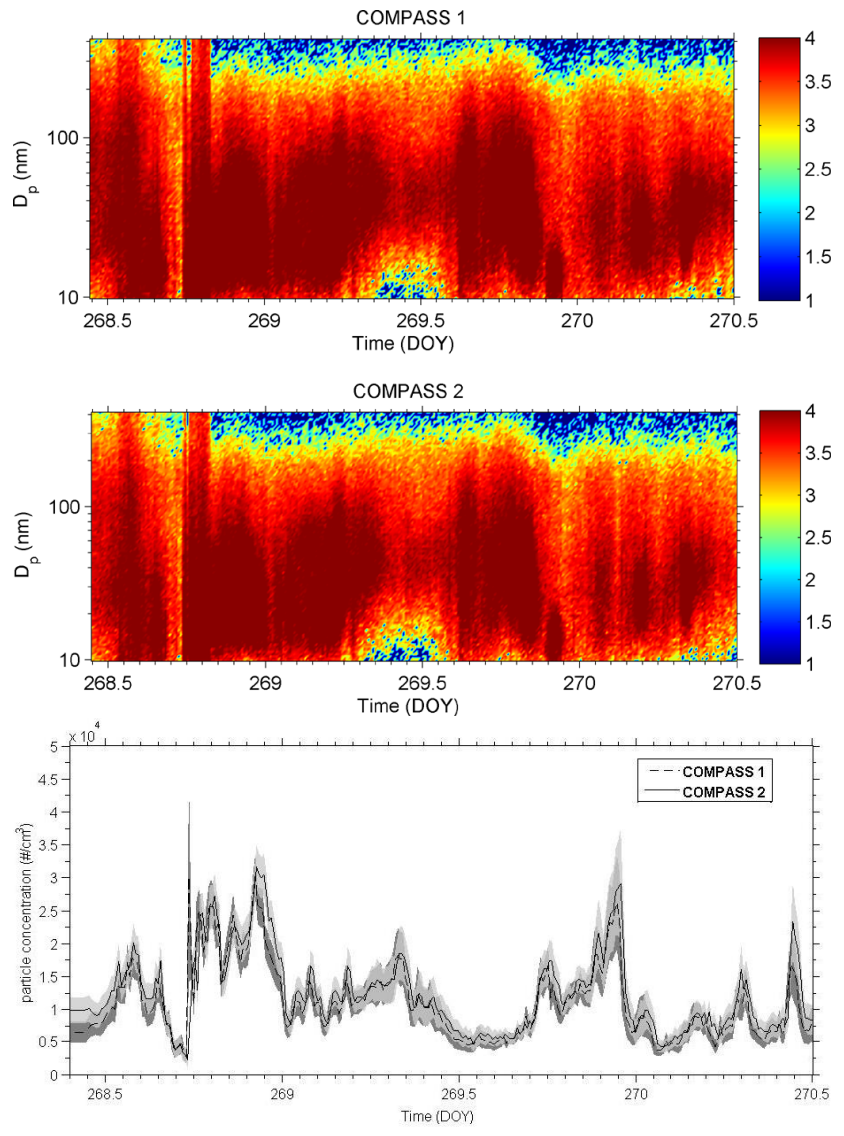

Fig. 6. Top and centre plots: particle size distribution $\mathrm{d} N / \mathrm{d} \log \left(D_{\mathrm{p}}\right)$ at non-modified conditions for both chambers to indicate similarity (DOY 268-270, 2012). The colour bar is logarithmic scaled. Bottom: same for total particle number concentration.

formation process is mainly influenced by exhaust gas from automobiles. In this case the primary chemical substances are BTEX, $\mathrm{NO}_{\mathrm{x}}, \mathrm{SO}_{2}$ and polycyclic aromatic hydrocarbons (PAHs).

The bottom graph in Fig. 6 shows the time-dependent particle concentration of both chambers. The maximal particle concentration occurs around evening time, at $3 \times$ $10^{4}$ particles $\mathrm{cm}^{-3}$. By contrast, the minimal particle concentration occurs about noontime, at $5000-10^{4}$ particles $\mathrm{cm}^{-3}$. The condition of higher traffic intensity during rush hour is supposed to control the height of the particle concentration at this time. In addition the uncertainty regions of both data series overlap continuously. So there are no significant differences between the measured particle concentrations of the two chambers.

\section{Comparative measurements}

For testing and investigation purposes, the novel twin chamber set-up was applied in two different environments: (a) the urban environment of Frankfurt am Main at the university campus Riedberg (September/October 2012) and (b) the remote biogenically affected area at Taunus Observatory (Mt. Kleiner Feldberg, $825 \mathrm{~m}$ a.s.l.) at a spruce forest site during spring 2013.

\subsection{Urban environment (Frankfurt am Main)}

The experiment conducted in Frankfurt was operated in two phases: phase 1 addressed an artificial rise in ambient ozone by positioning a pen-ray lamp with a wavelength of $253.7 \mathrm{~nm}$ in the inlet section (uppermost part) of COMPASS2, with protection from the lamps light for the reference chamber. Phase 2 focused on the impact of solar radiation by covering COMPASS2 with aluminium foil to prevent radiation and heat from penetrating inside.

\subsubsection{Phase 1 - test of urban conditions: ozone enhancement}

The impact of ozone was investigated between DOY 287.5 to 288.5 (start of October) and during a repetition in late November. The ozone mixing ratio climbed to values of 700$800 \mathrm{ppb}_{\mathrm{v}}$ in the modification chamber 2 and particle number concentrations increased to a up to a concentration tenfold greater than that of reference chamber 1 (Fig. 7). It is of interest that the particular enrichment does not only occur at daytime, but also at nighttime, although the ozone value enrichment was generally smaller than the maximum during 287 at noon $\left(800 \mathrm{ppb}_{\mathrm{v}}\right)$. This indicates a significant interaction of ozone with not only direct particle precursor compounds, but also nitrogen oxide species during night. Because of this $\mathrm{NO}_{3}$ levels are supposed to be remarkably enhanced in the modification chamber, leading to an enhanced oxidation capacity during the night. During daylight the increased ozone will be photolysed, intensifying the $\mathrm{OH}$ production and the $\mathrm{HO}_{\mathrm{x}}$-cycling $\left(\mathrm{OH}\right.$ and $\left.\mathrm{HO}_{2}\right)$ at the same time. The notable urban NO sink of these radicals is remarkably reduced due to their conversion to the less reactive and therefore longerlived $\mathrm{NO}_{2}$. A repetition in November showed similar but weaker increases in ozone as well as in number concentrations, indicating different source strength of precursors and smaller reaction rates. The volume concentration displayed a similar pattern and behaviour as the number concentration. However, the increase with ozone enrichment was less intense.

Figure 7 shows the measured ozone mixing ratio (panel a), particle concentration (panel b) and particle volume concentration (panel c) in both chambers during the ozone experiment. In Fig. 7a, an increase of the ozone mixing ratio is observed in COMPASS2, reaching a maximum of nearly $700 \mathrm{ppb}_{\mathrm{v}}$. In contrast to that the ozone mixing ratio in COMPASS1, which measured continuously under atmospheric background conditions, stayed at a quite lower level (around $30 \mathrm{ppb}_{\mathrm{v}}$ ). The maximal ozone mixing ratio in COMPASS2 occurred at about the time period DOY 287.5. After 

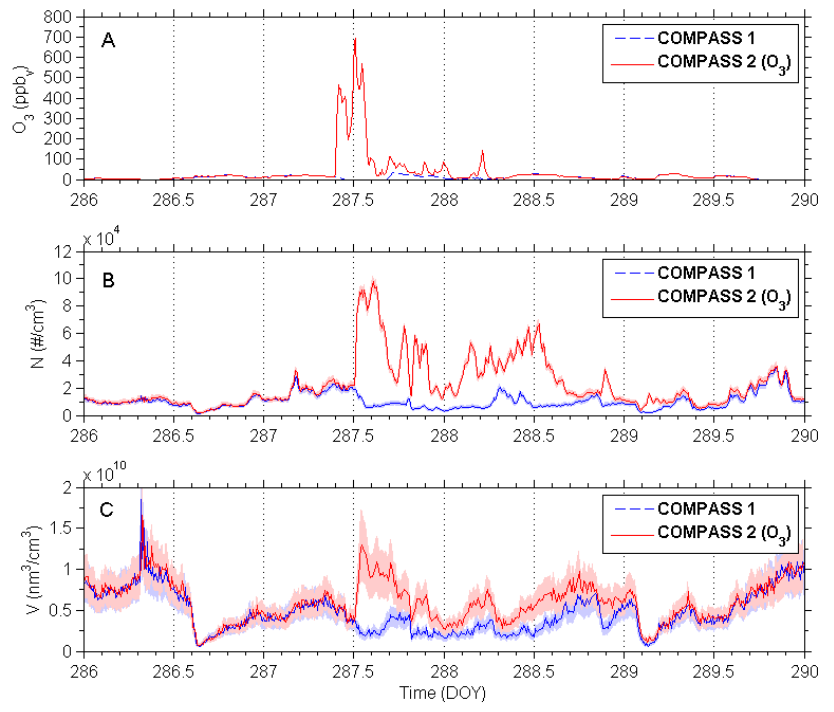

Fig. 7. Urban air (Frankfurt am Main): ozone mixing ratio (A), particle concentration $(\mathbf{B})$ and particle volume concentration $(\mathbf{C})$ during the ozone enhancement experiment (DOY 286-290). The ozone mixing ratio was increased in chamber 2 by pen ray $(\lambda=253.7 \mathrm{~nm})$.

that it decreased to nearly $100 \mathrm{ppb}_{\mathrm{v}}$, which is still higher than the ozone mixing ratio in COMPASS1 by factor of 3. Regarding particle concentration (Fig. 7b) there were no differences at the time period DOY 286-287.5, when the ozone mixing ratio was not increased. With the addition of ozone to COMPASS2, an increase in the particle concentration (up to a maximum of $10^{5}$ particles per $\mathrm{cm}^{3}$ ) was observed. In the reference chamber, COMPASS1, the particle concentration stayed at quite low levels. The complete particle size distribution between 9.6 and $422 \mathrm{~nm}$ in spherical diameter is provided in Fig. 8. The significance of the increase is apparent when comparing both data series between DOY 287.5 and 288.5. This is apparent in the scatter plot of measured ozone vs. total particle number concentration in both chambers (Fig. 9), too. A clear positive relationship for $30 \mathrm{~min}$ averaged time intervals is visible. For this plot six extraordinary ozone mixing ratios above $600 \mathrm{ppb}_{\mathrm{v}}$ with huge error bars have been excluded. Please note that because ozone is not the direct particle precursor, but is involved in a set of chemical reaction steps depending on $\mathrm{NO}_{\mathrm{x}}$ as well as VOCs, no linear behaviour was expected or observed.

In case of the particle volume concentration, there is a trend of rising identical to that of the particle concentration. The volume concentration in the COMPASS 2 is significantly higher than in COMPASS2 during the ozone enrichment period (Fig. 7, lower plot).

Both increases, i.e. in particle number and volume concentrations, at elevated ozone mixing ratios result in a significant increase in mode diameters of the particle number concentration (Fig. 10). The fitting was performed with Gaussian type curves at a maximum number of 3 . In cases in which

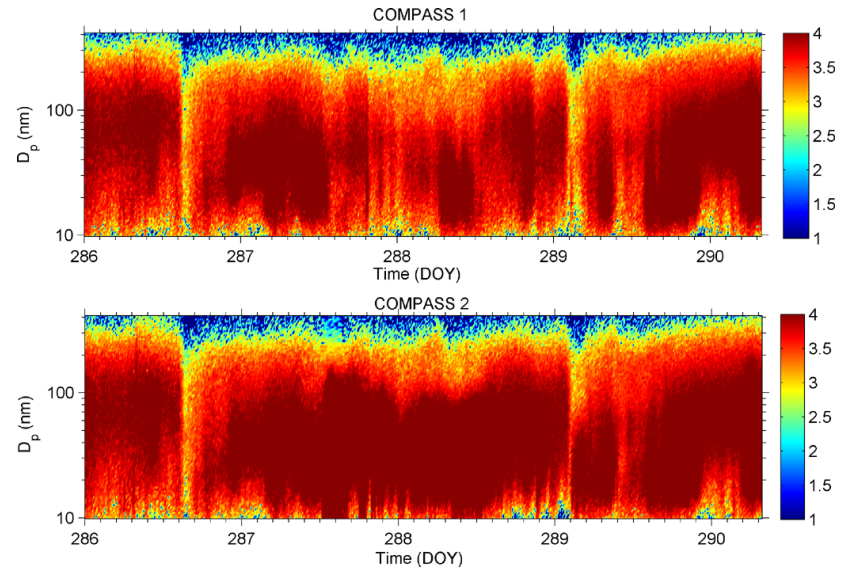

Fig. 8. Particle size distribution plots during the urban ozone enhancement experiment between the modified (COMPASS2, lower plot) and reference chamber (COMPASS1, upper plot). The colour bar displays the logarithmic scaled $\mathrm{d} N / \mathrm{d} \log \left(D_{\mathrm{p}}\right)$ values.

a smaller number caused a better fit, the number of modes was reduced (Hussein et al., 2005). Atmospheric and elevated ozone derived values are marked with two different colours, the atmospheric ozone derived ones in black and the elevated ozone derived values in red. Please not the different symbols for individual modes.

Figure 11 shows the cross-correlation between the difference of particle concentration and ozone mixing ratio in both chambers. A clear correlation between these two parameters is observed with the maximal cross-correlation coefficient of 0.9 at a time shift of $(0.34 \pm 0.17) \mathrm{h}$ or $(20 \pm 10) \mathrm{min}$. The values of time shift above $0.34 \mathrm{~h}$ correspond to times at which the residence time of $26 \mathrm{~min}$ inside the chamber was exceeded. The scatter plot of the ozone concentration ratio of both chambers vs. the particle number concentration ratio indicates a linear rise by a factor of $2.8 \pm 0.3$ for the city of Frankfurt at the start of October 2012. This means that if ozone increases by $10 \%$, the particle number concentration would rise by about $30 \%$, indicating that ozone is an important pollutant and precursor for ambient particles.

\subsubsection{Phase 2 - tests at urban conditions: impact of solar radiation}

A further impact factor for - especially urban - particle formation is solar radiation, since it controls atmospheric transport and chemical reactions. While $\mathrm{OH}$ is formed with increasing radiation, several products degrade in its presence. In order to investigate this effect, the modification chamber 2 was covered by an aluminium foil to prevent (a) the penetration of sunlight and (b) a temperature increase of the covered chamber due to isolation. In fact the chamber was found to be significantly cooler during the day $\left(50^{\circ} \mathrm{C}\right.$, nonshaded measurements) than the reference chamber $\left(20^{\circ} \mathrm{C}\right.$ in darkened chamber) and with identical temperatures at night. 


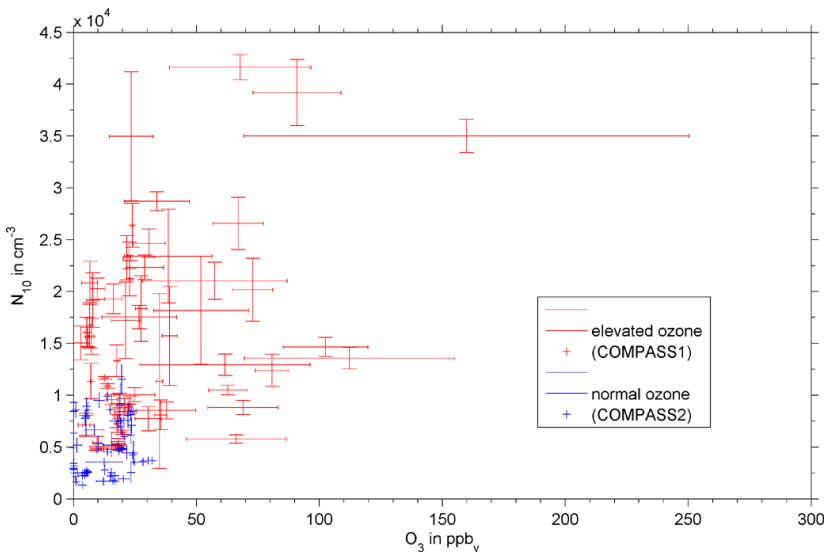

Fig. 9. Scatter plot of measured ozone mixing ratios and total particle number concentrations above a diameter of $9.6 \mathrm{~nm}$ as $30 \mathrm{~min}$ averages in both chambers (unchanged in blue, elevated ozone in red). Three outliers between 600 and $800 \mathrm{ppb}$ of ozone have been excluded.
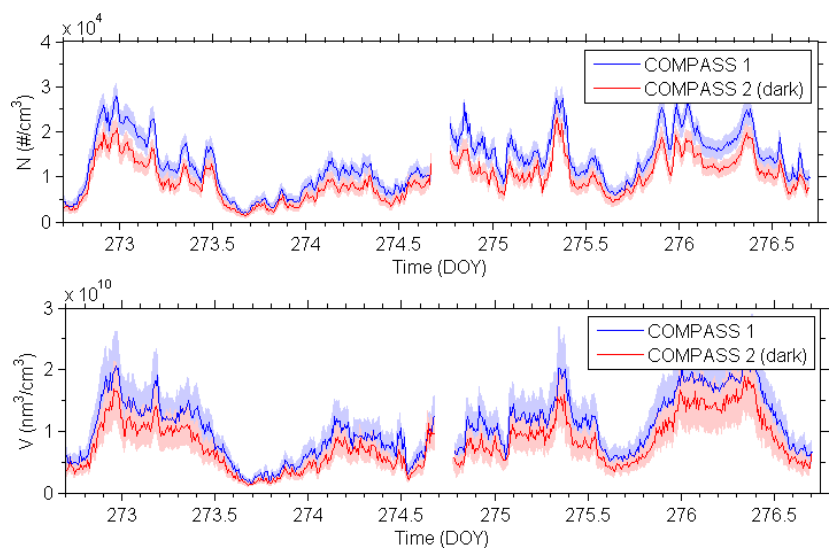

Fig. 10. Mean mode diameters fitted to particle number size distributions measured in both COMPASS chambers. Elevated ozone is displayed in red, while normal conditions are shown in black.

Consequently the saturation vapour pressure of aerosol phase affine compounds drops and the chemical lifetime of reactive aerosol species increases. By contrast, new potential aerosol material is formed by hydroxyl radical reactions in the reference chamber. Comparing the importance of both aspects, the $\mathrm{OH}$ contribution seems evidently more important for (a) the number but also for (b) mass and volume, although warmer temperatures were present (Fig. 12). Both were lower in the covered chamber (COMPASS2) compared to the reference one (COMPASS1) except during night when no difference between the two chambers could be found. This is in line with the expectations.

Both investigations in the urban area of Frankfurt clearly demonstrate that ozone and solar radiation lead to an enhanced particle number and mass concentration, i.e. issues for public health and therefore potential future problems.

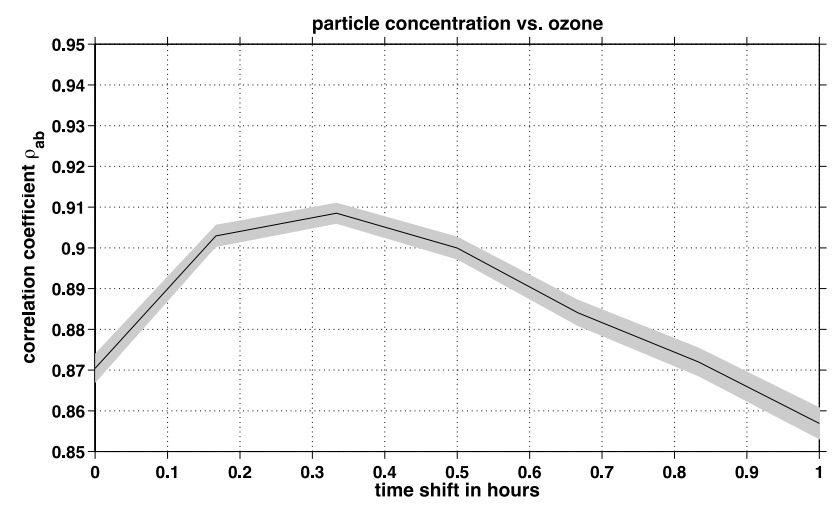

Fig. 11. Cross-correlation of measured particle number concentration and ozone volume mixing ratio difference between COMPASS2 (modified) and COMPASS1 (reference) during the ozone enrichment experiment (DOY 286-290, 2012).
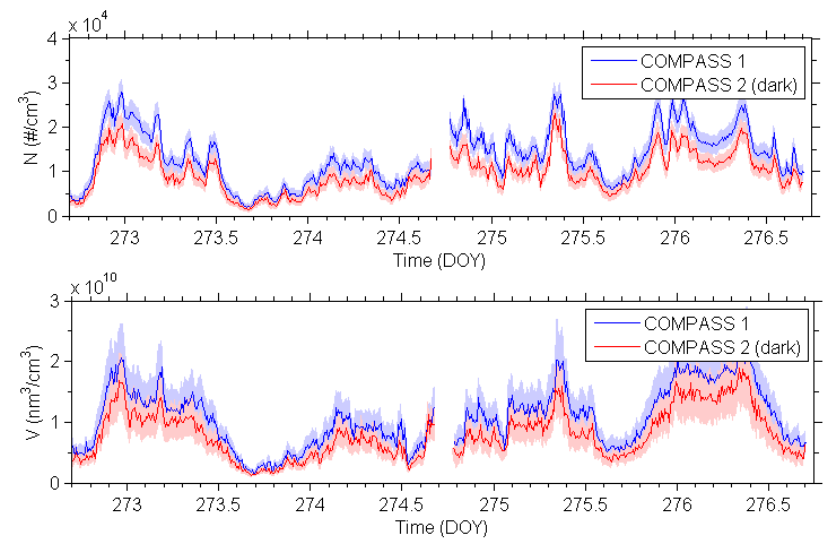

Fig. 12. Particle number and volume concentration measurements during the period during which COMPASS2 was shaded from sunlight at urban conditions.

\subsection{Remote region: Taunus Observatory, spruce forest}

\subsubsection{Impact of solar radiation and ozone}

For investigating the local effect of ozone on new particle formation, a pen-ray with a wavelength maximum at 253.7 $\mathrm{nm}$ was mounted at the inlet of COMPASS2 and shielded in the direction of the reference chamber COMPASS1 in an identical way as was done for urban experiments.

In this period of observation, two phases were chosen: (A) only ozone was enriched and (B) ozone was enriched and radiation was reduced in COMPASS2.

\section{Phase A - tests at remote conditions:} (a) ozone enrichment

Because of the pen-ray lamp, the ozone value in COMPASS2 was kept constant above $100 \mathrm{ppb}_{\mathrm{v}}$ (at minimum 1.5 to threefold of the ambient mixing ratio in COMPASS1). There was 

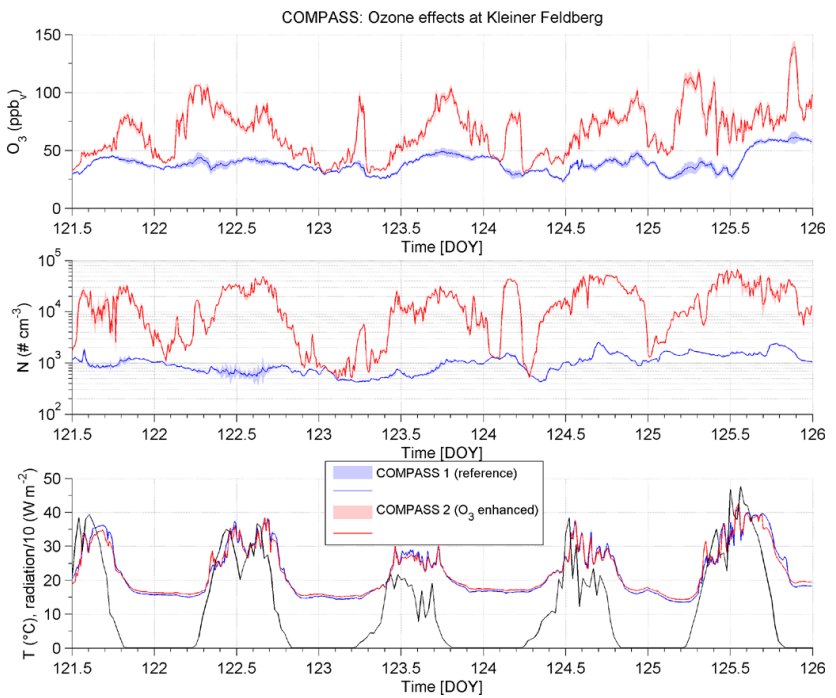

Fig. 13. Remote conditions at Taunus Observatory, Phase A: (top) Ozone mixing ratio in COMPASS1 (reference) and COMPASS2 (Ozone enhancement). (centre) Particle number concentration during the ozone increase experiment in both chambers and (bottom) temperature and global radiation in both chambers.

only a moderate increase at nighttime i.e. especially during periods with a relative humidity close to $100 \%$, and the ozone was most intense during daytime at driest environmental conditions. The ambient ozone mixing ratio itself displayed a typical daily cycle, varying between $30 \mathrm{ppb}_{\mathrm{v}}$ at minimum and $60 \mathrm{ppb}_{\mathrm{v}}$ at maximum (mean: $47.9 \pm 6.1 \mathrm{ppb}_{\mathrm{v}}$ ) in the reference chamber. The temperature in both chambers was $18.1 \pm 6.2^{\circ} \mathrm{C}$ and no significant difference was observed between the two enclosures $\left(\Delta T=0.4 \pm 0.6^{\circ} \mathrm{C}\right)$. The same applies for the relative humidity $(\mathrm{RH})$ that was measured as $59 \pm 26 \%$ with a difference of $\Delta \mathrm{RH}=0 \pm 2 \%$.

\section{Particles}

With respect to total particle number concentration $(N)$ the observations are evident above $3 \mathrm{~nm}$ in diameter. In every case ozone is significantly enhanced, (Fig. 13a) the total particle number concentration increased remarkably (ca. $+75 \% \mathrm{ppb}_{\mathrm{v}}{ }^{-1}$ of ozone increase, Fig. 13b). While temperatures and relative humidity in both chambers are measured identically (Fig. 13c) and no indication for a difference in solar radiation is available, the presence of ozone and thus a subsequent reaction with an aerosol particle precursor gas evidently causes the increase. In some cases the measured particle number concentration even exceeded the upper detection limit of the particle counter $\left(10^{5} \mathrm{\#} \mathrm{cm}^{-3}\right)$ (Fig. 13b) and no further rise could be quantified.
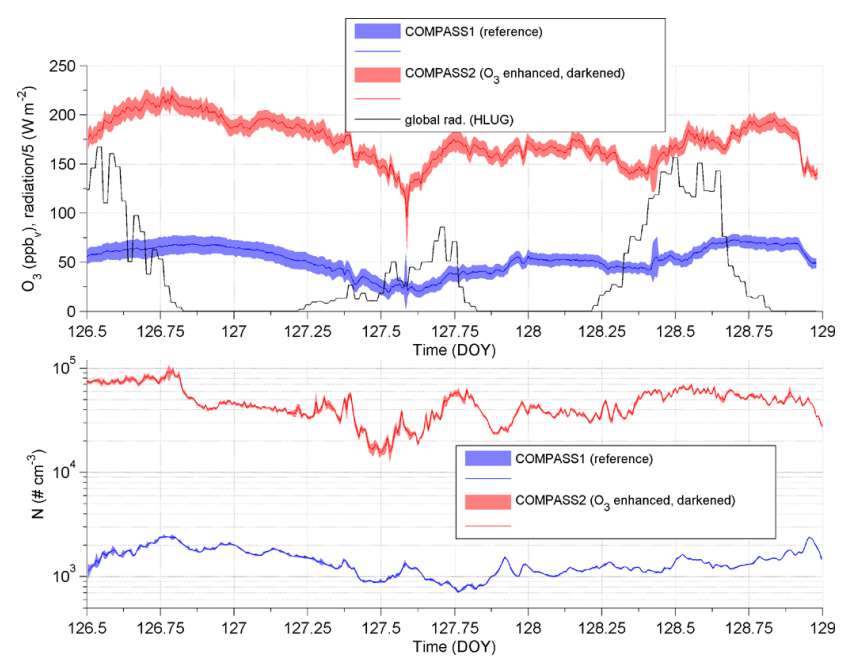

Fig. 14. Ozone enhancement and reduction of solar radiation in COMPASS2 at Taunus Observatory, Phase 2: (top) ozone mixing ratios in COMPASS 1 and 2 as well as global radiation at the site of interest. (bottom) Effect on particle concentration measured.

Gases

When enhancing only ozone, several oxidative VOCs (presumably oxidation products of terpenoids such as monoand sesquiterpenes) indicate a clear rise (Table 5): formand acetaldehyde, acetone and the molar mass 72 (potentially propene, butanal or butanone). Formic acid increases while acetic acid decreases. No clear change is observable for mono- and sesquiterpenes, although a tendency for reduction is apparent. This can be understood especially for sesquiterpenes because of their primary constituent, $\beta$ caryophyllene, and the short atmospheric lifetime (of less than a minute) and the scattering of observations around detection limit (ca. 10-20 ppt $_{\mathrm{v}}$ ). These reactive gases will not pass the enclosure. But the notable increase of oxidation products within the residence time of ca. 27 min within the chambers indicates a notable chemical conversion and time for further growth. The surrounding forest (i.e. spruce) is no predominant isoprene emitter, and so a difference of very small mixing ratios is hardly detectable.

\section{Phase B - tests at remote conditions: ozone enrichment and solar radiation reduction}

\section{Particles}

When increasing ozone and reducing solar radiation, the situation appears similar to how it is in the case of ozone only (Fig. 14). There is still a rise in total number. Although the length of the data set is less extensive than it is for the ozone-only experiment (Phase A), the same characteristics are apparent. Both factors, i.e. ozone and solar radiation, seem important for the observed increase. In 
Table 5. Impact of solar radiation and ozone on VOC mixing ratios observed. Bold marked values indicate significant changes.

\begin{tabular}{|c|c|c|c|c|c|c|c|}
\hline \multirow[b]{2}{*}{ Molar mass } & \multirow[b]{2}{*}{ Compound } & \multicolumn{3}{|c|}{$\begin{array}{l}\text { COMPASS2/COMPASS1 at } \\
\text { elevated ozone }\end{array}$} & \multicolumn{3}{|c|}{$\begin{array}{c}\text { COMPASS2/COMPASS } 1 \text { at elevated } \mathrm{O}_{3} \\
\text { and reduced radiation }\end{array}$} \\
\hline & & Nighttime (\%) & Daytime (\%) & All (\%) & Nighttime & Daytime & All \\
\hline 30 & Formaldehyde & $+31.5 \pm 19.7$ & $+20.0 \pm 11.1$ & $25.5 \pm 16.0$ & $+48.3 \pm 6.4$ & $+35.4 \pm 12.4$ & $+39.8 \pm 12.3$ \\
\hline 32 & Methanol & $+4.5 \pm 4.1$ & $+2.7 \pm 3.2$ & $+3.3 \pm 3.4$ & $-7.4 \pm 2.6$ & $-10.1 \pm 4.0$ & $-9.1 \pm 3.8$ \\
\hline 44 & Acetaldehyde & $+\mathbf{1 1 . 7} \pm \mathbf{5 . 0}$ & $+8.4 \pm 5.9$ & $+9.9 \pm 5.4$ & $+5.6 \pm 2.5$ & $+5.8 \pm 5.8$ & $+5.7 \pm 4.9$ \\
\hline 46 & Formic acid & $-0.4 \pm 2.4$ & $+0.6 \pm 11.1$ & $-0.2+2.5$ & $+1.8 \pm 2.0$ & $+1.6 \pm 4.0$ & $+1.7 \pm 3.5$ \\
\hline 58 & Acetone & $+9.6 \pm 5.1$ & $+5.0 \pm 5.2$ & $+6.9 \pm 5.3$ & $+4.7 \pm 2.0$ & $+5.2 \pm 4.5$ & $+\mathbf{5 . 0} \pm \mathbf{3 . 8}$ \\
\hline 60 & Acetic acid & $-9.1 \pm 6.8$ & $-7.6 \pm 9.5$ & $-8.8 \pm 5.7$ & $+10.4 \pm 5.4$ & $+4.9 \pm 8.4$ & $+6.8 \pm 8.0$ \\
\hline 66 & $\begin{array}{l}\text { Cyclopentadiene, } \\
\text { malononitrile }\end{array}$ & $-9.4 \pm 33.3$ & $-5.4 \pm 30.8$ & $-6.7 \pm 31.6$ & $+11.4 \pm 53.9$ & $+21.5 \pm 49.4$ & $+18.0 \pm 51.1$ \\
\hline 68 & Isoprene & $+1.3 \pm 7.8$ & $+2.1 \pm 8.1$ & $+1.6 \pm 7.6$ & $+0.8 \pm 6.0$ & $+1.3 \pm 7.4$ & $+1.1 \pm 6.9$ \\
\hline 72 & $\begin{array}{l}\text { 1-propene, butanal, } \\
\text { 2-butanone }\end{array}$ & $+13.7 \pm 9.4$ & $+7.6 \pm 7.3$ & $+\mathbf{1 0 . 5} \pm 8.3$ & $+2.6 \pm 3.6$ & $+2.9 \pm 5.2$ & $+2.8 \pm 4.7$ \\
\hline 78 & Benzene & $+23.4 \pm 39.8$ & $+20.0 \pm 37.5$ & $+21.8 \pm 31.3$ & $+25.6 \pm 34.0$ & $+25.9 \pm 38.4$ & $+25.8 \pm 36.8$ \\
\hline $81^{*}$ & MT fragment & $-5.0 \pm 7.3$ & $-1.7 \pm 8.5$ & $-3.4 \pm 7.6$ & $-8.4 \pm 7.5$ & $-8.0 \pm 9.6$ & $-8.2 \pm 8.9$ \\
\hline 92 & Toluene & $-0.5+30.6$ & $+1.9 \pm 28.9$ & $+1.3 \pm 29.9$ & $-5.8 \pm 27.6$ & $+3.1 \pm 25.2$ & $\pm 0 \pm 26.3$ \\
\hline 136 & Monoterpenes (MT) & $-5.2 \pm 15.5$ & $-1.9 \pm 16.0$ & $-3.4 \pm 15.3$ & $-7.7 \pm 15.3$ & $-11.7 \pm 16.9$ & $-10.3 \pm 16.4$ \\
\hline 138 & Nopinone, sabina ketone & $+5.7 \pm 44.3$ & $+2.5 \pm 40.9$ & $+4.3 \pm 43.5$ & $+11.9 \pm 46.3$ & $+7.7 \pm 41.5$ & $+9.2 \pm 43.2$ \\
\hline 152 & Methyl salicylate & $+24.6 \pm 80.3$ & $+15.4 \pm 84.7$ & $+17.4 \pm 82.0$ & $+22.8 \pm 88.2$ & $+31.9 \pm 94.6$ & $+28.8 \pm 92.2$ \\
\hline 154 & Linalool & $+8.6 \pm 50.3$ & $+1.9 \pm 46.8$ & $+3.75 \pm 46.5$ & $+1.6 \pm 36.6$ & $-0.3 \pm 32.1$ & $+0.4 \pm 33.6$ \\
\hline 204 & Sesquiterpenes & $-7.0 \pm 36.1$ & $-7.0 \pm 36.1$ & $-7.2 \pm 37.3$ & $+5.5 \pm 31.6$ & $+7.5 \pm 36.9$ & $+6.8 \pm 35.1$ \\
\hline
\end{tabular}

order to quantify the individual contributions the correlation coefficient $\rho$ has been calculated for the rise in ozone as well as the present radiation in COMPASS1 (reference) and the particle number increase. Both values show a significant dependency: $\rho\left(\Delta \mathrm{O}_{3}, \Delta \mathrm{N}\right)=73.8 \pm 0.4$ at no time difference and $\rho$ (radiation, $\Delta \mathrm{N})=79.6 \pm 0.3$ at identical time. However the correlation increases up to a value of $83.9 \pm 0.3$ with a time shift (radiation earlier) by about $2.7 \mathrm{~h}$. This indicates an earlier production of precursor gases by radiation or radiation-initiated chemistry $(\mathrm{OH})$ in anticipation of some ideal conditions, such as the potential activation of nuclei. Thus, the ozone effect, where the correlation clearly declines with time shift between rise in ozone and in particles, is the limiting step. This becomes obvious in Fig. 15, in which the relative particle number enhancement in the case of the ozone-only experiment is split into different times of the day (day- and nighttime). The daytime data display a higher slope (ca. $+100 \%$ per $\mathrm{ppb}_{\mathrm{v}}$ of ozone) than the nighttime data (ca. $+17 \%$ per $\mathrm{ppb}_{\mathrm{v}}$ ozone), again indicating the importance of solar radiation - potentially for $\mathrm{OH}$ and further radical production, but perhaps not during the residence time in the flow chambers. In this context it is interesting to note that the increase of ozone seems to occur primarily above ca. $35 \mathrm{ppb}_{\mathrm{v}}$ of ambient ozone. This indicates a link to the ozone stress-related emission of sesquiterpenes (Bourtsoukidis et al., 2012).

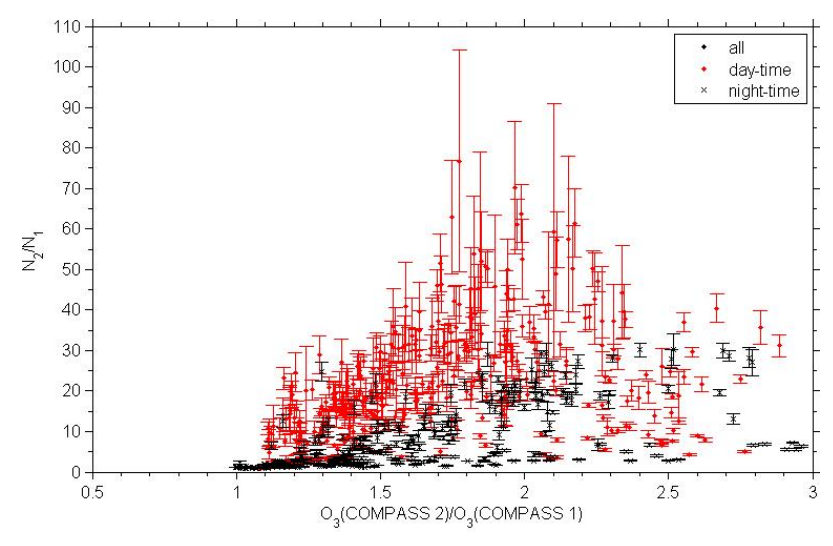

Fig. 15. Scatter plot of relative ozone vs. relative particle number increase at different times in COMPASS.

Gases

In this phase i.e. reduction of solar radiation, the observations were slightly different than the previous ones (Table 5). Although both of the smallest aldehydes were observed to increase in the presence of ozone, too, methanol clearly reduced. Terpenes and their larger oxidation products only provide a tendency for reduction of terpenes and increase of oxidation products that is in line with enhanced ozone mixing ratios and presumably intensified atmospheric reactions in chamber 2 . It is worth mentioning that the presence of $\mathrm{NO}_{\mathrm{x}}$ may cause notable contributions of the nitrate radical reactions in the dark (solar radiation reduction, chamber 2). 


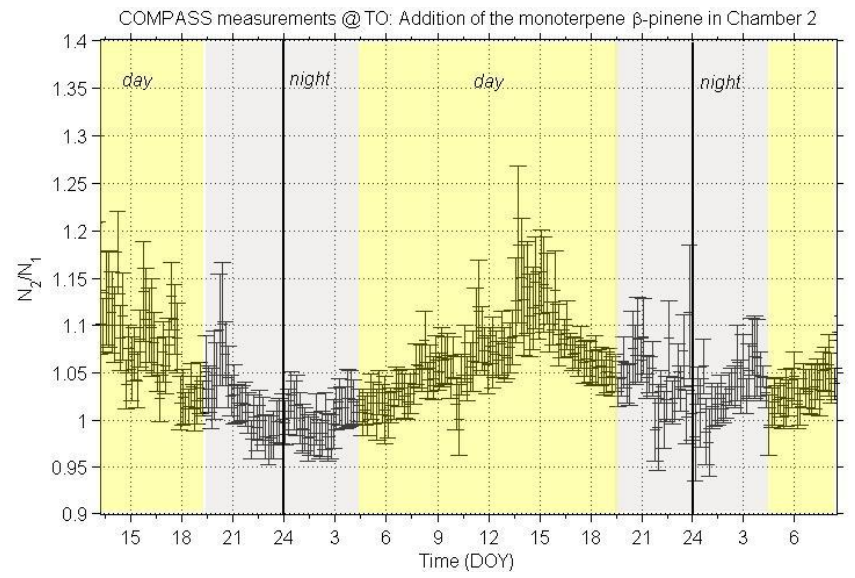

Fig. 16. Phase 3: experiment with external monoterpene (upper plot) supply to COMPASS2. Upper plot: monoterpene mixing ratio at the end of each chamber. Bottom plot: the ratio of $10 \mathrm{~min}$ averaged particle number concentrations of COMPASS 2 to those of COMPASS1.

\section{Impact of BVOCs}

To test the influence of volatile organic compounds (VOCs) and their oxidation products on particle formation, two different biogenic VOCs were selected: (1) the monoterpene $\left(\mathrm{C}_{10} \mathrm{H}_{16}\right) \beta$ pinene, which is expected to react primarily with ambient $\mathrm{OH}$-radicals (approximated daily average: ca. $80 \%$ oxidation by $\mathrm{OH}$ ), and (2) the sesquiterpene (SQT, $\mathrm{C}_{15} \mathrm{H}_{24}$ ) $\beta$ caryophyllene, which is known to be quickly oxidised by the present ozone molecules (ca. $95 \%$ of total sink). Next to the addition, the monoterpene is expected to start reacting with either of the two radicals (daytime: $\mathrm{OH}$, nighttime: $\mathrm{NO}_{3}$ ). This leads to the formation of large organic peroxy radicals $\left(\mathrm{RO}_{2}\right)$ and several longer-lived products such as nopinone. By contrast, the sesquiterpene reacts with ambient ozone, forming a large variety of products e.g. the Criegee intermediates (Criegee, 1975) and the intramolecularly formed secondary ozonide (Beck et al., 2011). Both biogenic volatile organic compounds (BVOCs) were added in a small bypass air flow of $(10 \pm 1) \mathrm{cm}^{3} \mathrm{~min}^{-1}$ to COMPASS2 using a permeation oven at a defined temperature. The oven temperature was set to $(29 \pm 0.2)^{\circ} \mathrm{C}$ in the case of the monoterpene (Phase C) and to $(47.8 \pm 0.2)^{\circ} \mathrm{C}$ in the case of the sesquiterpene (Phase D). Both compounds were monitored by the PTR-MS instrument at the outlet of the chamber.

During both terpene-addition related phases (C and D), temperature and humidity in both chambers were identical within the measurement uncertainties. This is why we will focus primarily on the gaseous, i.e. VOC, measurements. The VOCs measured by PTR-MS displayed several significant changes. Those are briefly summarised in Table 6 and will be discussed in the corresponding "Gases" sections following.

\section{Phase $\mathrm{C}$ - tests at remote conditions: monoterpene addition}

Gases

While a clear rise in monoterpene signal could be observed in phase C (Table 4, left), further VOCs indicated a clear rise either during nighttime or the entire time. The ones increasing all the time were methanol and mass $66 \mathrm{~g} \mathrm{~mole}^{-1}$ (pres. cyclopentadiene or malononitrile), while formaldehyde, isoprene and toluene only displayed a significant change during nighttime. All of these observations may result from three different processes: (a) increased production by a specific monoterpene compared with a mixture of monoterpenes in the atmosphere, (b) a change in local sink intensity, i.e. a significant reaction with with $\mathrm{OH}$ but not with ambient $\mathrm{NO}_{3}$ and finally (c) lower source intensities i.e. lower emission and meteorological transport at nighttime. Further masses, such as nopinone, indicated trends but remained below the range of significance (one standard deviation).

\section{Phase D - tests at remote conditions: sesquiterpene addition}

\section{Gases}

In the case of sesquiterpene addition, no significant changes have been monitored for any VOC (Table 6, right). However, the ozone mixing ratio dropped due to the reaction with the sesquiterpene. Because of the very short lifetime of $\beta$ caryophyllene (ca. $45 \mathrm{~s}$ ), the increase was assumed to be identical with the drop in the ozone mixing ratio. Our observations indicate a rise between 0 and $(4.5 \pm 1.5) \mathrm{ppb}_{\mathrm{v}}$. As for monoterpene addition, several masses, i.e. presumable oxidation products of $\beta$ caryophyllene with ozone, displayed trends (e.g. in formaldehyde) but remained within the uncertainty range. Since the competitors in the case of ozone reactions are minor, the effects were found to be non-significant for other VOCs. But oxidation products with ozone are expected to be rather non-volatile and effects will primarily occur in the aerosol phase.

\section{Particles}

It is very interesting to see the different impacts of both terpenes on the ambient particle number concentration (Figs. 16-18). While the monoterpene addition results in a clear daily profile, with a maximum increase around noon $(+20 \pm 5 \%)$ when the most intense radiation occurs and evidently no change during nighttime conditions (Figs. 16 and 17), the sesquiterpene addition creates a nearly constant increase by about $+13 \pm 4 \%$ except between 10:00 p.m. and 02:00 a.m.LT (Figs. 17 and 18). The observations may be explained by a two-stage process that can be 
Table 6. Impact of monoterpene ( $\beta$ pinene) addition on the VOC mixing ratios observed. Bold marked values indicate significant changes. Sesquiterpene ( $\beta$ caryophyllene) addition did not show any significant changes due to high reactivity of SQTs and the fact that it was added in smaller amounts.

\begin{tabular}{|c|c|c|c|c|}
\hline \multirow{2}{*}{$\begin{array}{l}\text { Molar mass } \\
\left(\mathrm{g} \mathrm{mole}^{-1}\right)\end{array}$} & \multirow[t]{2}{*}{ Compound } & \multicolumn{3}{|c|}{ COMPASS2/COMPASS 1 at elevated MT } \\
\hline & & Nighttime (\%) & Daytime (\%) & All (\%) \\
\hline 30 & Formaldehyde & $+7.0 \pm 5.4$ & $+1.9 \pm 7.2$ & $+4.6 \pm 6.9$ \\
\hline 32 & Methanol & $-5.8 \pm 2.3$ & $+6.4 \pm 2.6$ & $-6.2 \pm 2.5$ \\
\hline 44 & Acetaldehyde & $-0.8 \pm 2.0$ & $+2.9 \pm 6.3$ & $+0.7 \pm 5.5$ \\
\hline 46 & Formic acid & $-0.4 \pm 2.4$ & $+0.5 \pm 3.3$ & $-0.1+2.8$ \\
\hline 58 & Acetone & $-0.5 \pm 1.6$ & $+1.5 \pm 4.9$ & $+0.8 \pm 4.1$ \\
\hline 60 & Acetic acid & $-0.2 \pm 0.4$ & $0.0 \pm 5.4$ & $+0.1 \pm 4.9$ \\
\hline 66 & Cyclopentadiene, malononitrile & $+217.7 \pm 96.6$ & $+\mathbf{1 2 3 . 5} \pm \mathbf{3 0 . 0}$ & $+168.9 \pm 125.5$ \\
\hline 68 & Isoprene & $+\mathbf{1 2 . 1} \pm 7.8$ & $+5.4 \pm 9.5$ & $+9.0 \pm 9.2$ \\
\hline 72 & 1-propene, butanal, 2-butanone & $-0.9 \pm 3.6$ & $-0.6 \pm 5.8$ & $+0.7 \pm 5.0$ \\
\hline 78 & Benzene & $+23.7 \pm 26.5$ & $+9.3 \pm 20.5$ & $+14.3 \pm 21.3$ \\
\hline $81^{*}$ & MT fragment & $+452.8 \pm 138.8$ & $+204.6 \pm 181.2$ & $+252.8 \pm 210.6$ \\
\hline 92 & Toluene & $37.1+15.5$ & $+20.0 \pm 24.1$ & $+30.6 \pm 22.1$ \\
\hline 115 & Proline & $-4.0 \pm 20.2$ & $+0.3 \pm 21.2$ & $-0.3 \pm 21.4$ \\
\hline 136 & Monoterpenes (MT) & $+461.3 \pm 143.5$ & $+222.3 \pm 190.2$ & $+300.1 \pm 212.1$ \\
\hline 138 & Nopinone, sabina ketone & $+10.0 \pm 12.9$ & $+1.5 \pm 15.2$ & $+5.8 \pm 15.0$ \\
\hline 148 & MBO, SQT fragment & $-0.8 \pm 6.5$ & $-0.1 \pm 5.9$ & $-0.2 \pm 6.1$ \\
\hline 152 & Methyl salicylate & $+11.5 \pm 67.1$ & $-0.1 \pm 40.8$ & $+0.1 \pm 42.1$ \\
\hline 154 & Linalool & $+2.3 \pm 23.7$ & $+0.7 \pm 21.3$ & $+2.1 \pm 22.3$ \\
\hline 168 & Pinonaldehyde, caronaldehyde, limona ketone & $+0.6 \pm 44.9$ & $+0.3 \pm 40.3$ & $+0.3 \pm 39.9$ \\
\hline 204 & Sesquiterpenes & $+2.2 \pm 18.9$ & $-0.8 \pm 17.5$ & $-1.4 \pm 18.1$ \\
\hline
\end{tabular}

* Primary fragment ion of monoterpenes.

limited at both stages, i.e. the cluster production or the activation. From our observations during the addition of the monoterpene, one would tend to say that the $\mathrm{OH}$ oxidation production takes place in the activation stage. By contrast the sesquiterpene-ozone production may contribute earlier and lack in activation around midnight, when favourable compounds such as $\mathrm{OH}-$ or $\mathrm{NO}_{3}$-driven products display a minimum. Because of that, secondary oxidation products which are important for aerosol mass production will be formed less (Li et al., 2011).

This shows evidence that both BVOCs take place in the ambient particle formation process. However, the stage of impact, i.e. in the cluster formation steps or the activation of clusters, cannot be elucidated by the current measurements, since the available aerosol instrumentation was insufficient for that. This requires detailed future studies with either ion instruments or a CPC battery with the smallest size range of particles. Nevertheless, the difference in daily pattern is in agreement with the assumption of a stable cluster pool production below $2.7 \mathrm{~nm}$ in diameter, and a solar-radiation $(\mathrm{OH})$ driven activation of these clusters.

\section{Conclusions}

The novel twin-chamber technique COMPASS has been shown to act as an appropriate tool for investigating the impact and the role of different parameters and gases in the particle formation process under a variety of different conditions. The system is not necessarily limited to particles, but can be operated for cloud nuclei or gas-phase studies as well. The magnitude of the observed change depends on the residence time required for the particular process studied. This can be achieved by flow variation between $2 \min (R e=1150)$ and tenths of minutes, limited by the required sample flow rates. The flow system provides a laminar flow field as shown by FLUENT simulations, and uses two identical chambers for the evaluation of results, i.e. one reference and one experimental chamber for modifications. Because of the parallel operating chambers, wall loss is a minor process and its contribution will become important only at long residence times. Characterisations of both individual chambers demonstrated no significant change between the chambers. Therefore it is evident that the two function in an identical manner and that their application for measurements under atmospheric conditions is reasonable.

First tests in urban and forest conditions have been conducted, which indicate a strong potential for applications, i.e. starting with figuring out the important gases for the earliest cluster formation, the activation and subsequent growth, and the set-up can be applied for studying the effects on ambient particles directly in ambient conditions (not in the laboratory) at reasonable concentrations. 

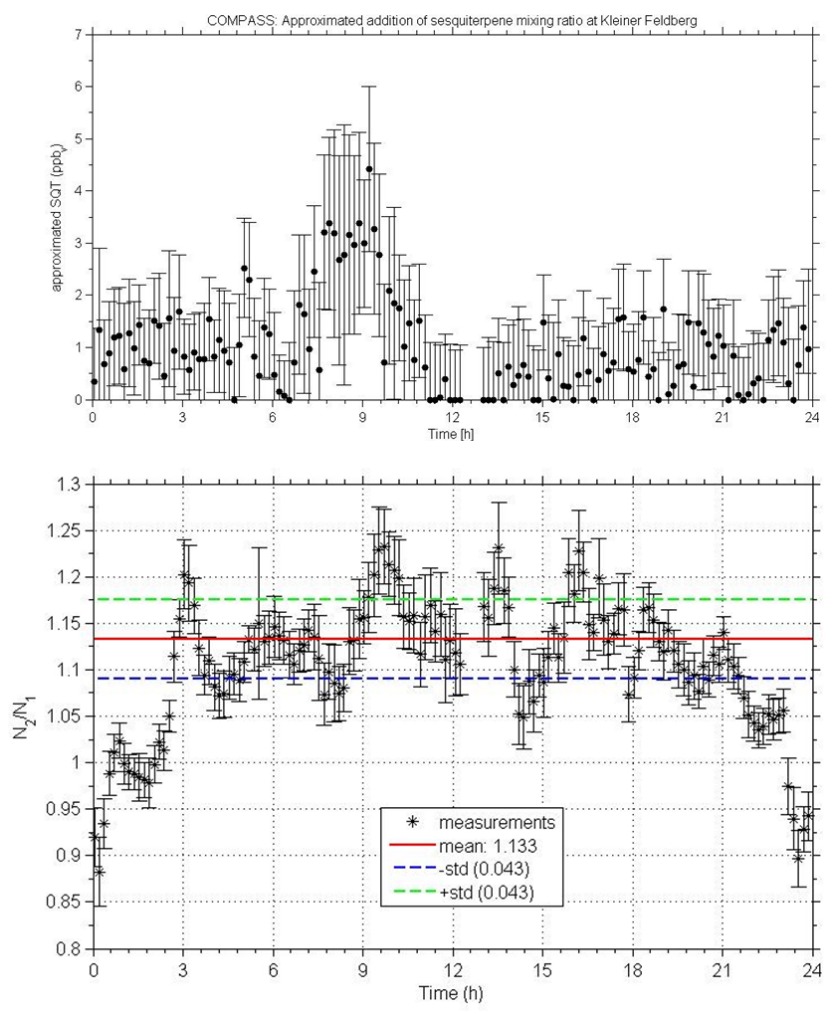

Fig. 17. Phase 4: experiment with external sesquiterpene supply to COMPASS2. Upper plot: additional sesquiterpene mixing ratio as approximated by the difference in ozone mixing ratio between both COMPASS chambers (reference-modified one). Bottom plot: the ratio of the $10 \mathrm{~min}$ averaged particle number concentrations of COMPASS2 to those of COMPASS1. Note the time shift due to the residence time in the chamber by ca. $0.5 \mathrm{~h}$.

Experiments in the urban air of Frankfurt clearly demonstrated the formation potential of particular number and mass based on ozone and solar radiation. Therefore this indicates a potential rise in particle mass during elevated ozone episodes as expected in future climate projections (Pachauri et al., 2007; Field et al., 2012). Based on our measurements in urban and forested regions an important role of ozone in new particle formation is evident. Suppressing solar radiation reduced the measured particle number and volume concentration. However, when both changes, i.e. ozone enhancement and radiation reduction, are overlapped, ozone seems dominant and may produce precursor gases or activating gases via an alternative pathway, such as $\mathrm{NO}_{3}$ production. Adding volatile organic compounds (VOCs) such as monoand sesquiterpenes lead to a clear rise in particle number, depending on the primary oxidant and the time of the day. While the monoterpene $\beta$ pinene reacts primarily with $\mathrm{OH}$ the particle enhancement displays the same pattern as solar radiation. By contrast, the sesquiterpene $\beta$ caryophyllene is oxidised by ozone resulting in a constant production of new particles. It is important to note that there is a minimum at

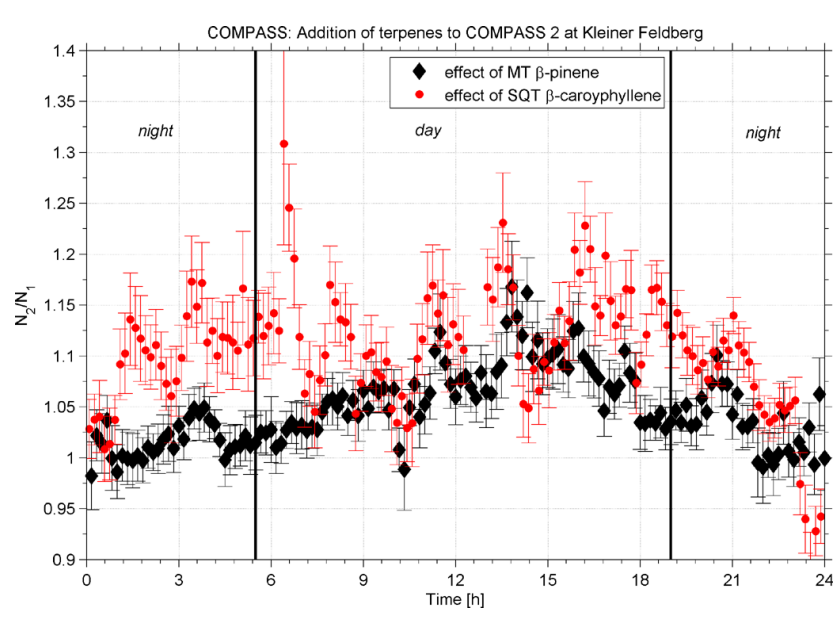

Fig. 18. Daily pattern of particle number concentration ratio of both chambers during both terpene additions, i.e. $\beta$ pinene (MT, $\mathrm{OH}$ reactive) in black dots and $\beta$ caryphyllene (SQT, ozone reactive) in red dots.

midnight although ozone remains fairly constant. However, the nitrogen oxides decline and the nitrate radical production is drastically reduced. This may explain that although clusters are available, the ozone oxidation products are incapable to activate those on their own without a radical initiated activation. Since these new particles will grow further to sizes at which they alter the Earth's radiation budget via cloud microphysics, the understanding of the processes involved are key to elucidating future climate changes.

This demonstrates the wide range of measurements possible that can increase understanding of the environmental processes affecting health, climate and feedback processes. The novel chamber seems to be an appropriate tool for that.

Acknowledgements. The authors would like to thank Efstratios Bourtsoukidis for support with respect to the PTR-MS measurements. Shang Sun was responsible for setting up the COMPASS chambers.

Edited by: H. Herrmann

\section{References}

Beck, M., Winterhalter, R., Herrmann, F., and Moortgat, G. K.: The gas-phase ozonolysis of $\alpha$-humulene, Phys. Chem. Chem. Phys., 13, 10970-11001, 2011.

Becker, K. H.: The European Photoreactor "EUPHORE", Final report, Contract EV5V-CT92-0059, European Community, Wuppertal, 1996.

Bonn, B. and Moortgat, G. K.: Sesquiterpene ozonolysis: Origin of atmospheric new particle formation from biogenic hydrocarbons, Geophys. Res. Lett., 30, 1585, doi:10.1029/2003GL017000, 2003. 
Bonn, B., Schuster, G., und Moortgat, G.: Influence of water vapor on the process of new particle formation during monoterpene ozonolysis, J. Phys. Chem., 106, 2869-2881, 2002.

Bonn, B., Korhonen, H., Petäjä, T., Boy, M., and Kulmala, M.: Understanding the formation of biogenic secondary organic aerosol from $\alpha$-pinene in smog chamber studies: role of organic peroxy radicals, Atmos. Chem. Phys. Discuss., 7, 3901-3939, doi:10.5194/acpd-7-3901-2007, 2007.

Bonn, B., Kulmala, M., Riipinen, I., Sihto, S.-L., and Ruuskanen, T. M.: How biogenic terpenes govern the correlation between sulfuric acid concentrations and new particle formation, J. Geophys. Res., 113, D12209, doi:10.1029/2007JD009327, 2008.

Bonn, B., Boy, M., Kulmala, M., Groth, A., Trawny, K., Borchert, S., and Jacobi, S.: A new parametrization for ambient particle formation over coniferous forests and its potential implications for the future, Atmos. Chem. Phys., 9, 8079-8090, doi:10.5194/acp-9-8079-2009, 2009.

Bonn, B., Bourtsoukidis, E., Sun, T. S., Bingemer, H., Rondo, L., Javed, U., Li, J., Axinte, R., Li, X., Brauers, T., Sonderfeld, H., Koppmann, R., Sogachev, A., Jacobi, S., and Spracklen, D. V.: The link between atmospheric radicals and newly formed particles at a spruce forest site in Germany, Atmos. Chem. Phys. Discuss., 13, 27501-27560, doi:10.5194/acpd-13-27501-2013, 2013.

Bourtsoukidis, E., Bonn, B., Dittmann, A., Hakola, H., Hellén, H., and Jacobi, S.: Ozone stress as a driving force of sesquiterpene emissions: a suggested parameterisation, Biogeosciences, 9, 4337-4352, doi:10.5194/bg-9-4337-2012, 2012.

Burkholder, J. B., Curtius, J., Ravishankara, A. R., and Lovejoy, E. R.: Laboratory studies of the homogeneous nucleation of iodine oxides, Atmos. Chem. Phys., 4, 19-34, doi:10.5194/acp-419-2004, 2004.

Criegee, R.: Mechanismus der Ozonolyse, Angew. Chem., 87, 765771, doi:10.1002/ange.19750872104, 1975.

Field, C. B., Barros, V., Stocker, T. F., Qin, D., Dokken, D. J., Ebi, K. L., Mastrandrea, M. D., Mach, K. J., Plattner, G.-K., Allen, S. K., Tignor, M., and Midgley, P. M. (Eds.): IPCC special report: Managing the Risks of Extreme Events and Disasters to Advance Climate Change Adaptation, Cambridge Univ. Press, Cambridge, UK, 2012.

Goldstein, A. H. and Galbally, I. E.: Known and unexplored organic constituents in the Earth's atmosphere, Environ. Sci. Technol., 41, 1514-1521, 2007.

Hirsikko, A., Nieminen, T., Gagné, S., Lehtipalo, K., Manninen, H. E., Ehn, M., Hõrrak, U., Kerminen, V.-M., Laakso, L., McMurry, P. H., Mirme, A., Mirme, S., Petäjä, T., Tammet, H., Vakkari, V., Vana, M., and Kulmala, M.: Atmospheric ions and nucleation: a review of observations, Atmos. Chem. Phys., 11, 767798, doi:10.5194/acp-11-767-2011, 2011.

Holzinger, R., Lee, A., Paw, K. T., and Goldstein, U. A. H.: Observations of oxidation products above a forest imply biogenic emissions of very reactive compounds, Atmos. Chem. Phys., 5, 67-75, doi:10.5194/acp-5-67-2005, 2005.

Hussein, T., Dal Maso, M., Petäjä, T., Koponen, I. K., Paatero, P., Aalto, P. P., Hämeri, K., and Kulmala, M.: Evaluation of an automatic algorithm for fitting the particle number size distributions, Boreal Environ. Res., 10, 337-355, 2005.

Hyvönen, S., Junninen, H., Laakso, L., Dal Maso, M., Grönholm, T., Bonn, B., Keronen, P., Aalto, P., Hiltunen, V., Pohja, T., Lau- niainen, S., Hari, P., Mannila, H., and Kulmala, M.: A look at aerosol formation using data mining techniques, Atmos. Chem. Phys., 5, 3345-3356, doi:10.5194/acp-5-3345-2005, 2005.

Jacobson, M. Z.: Fundamentals of atmospheric modeling, Cambridge University Press, 2nd Edn., Cambridge, USA, 2005.

Jimenez, J. L., Canagaratna, M. R., Donahue, N. M., Prevot, A. S. H., Zhang, Q., Kroll, J. H., DeCarlo, P. F., Allan, J. D., Coe, H., Ng, N. L., Aiken, A. C., Docherty, K. S., Ulbrich, I. M., Grieshop, A. P., Robinson, A. L., Duplissy, J., Smith, J. D., Wilson, K. R., Lanz, V. A., Hueglin, C., Sun, Y. L., Tian, J., Laaksonen, A., Raatikainen, T., Rautiainen, J., Vaattovaara, P., Ehn, M., Kulmala, M., Tomlinson, J. M., Collins, D. R., Cubison, M. J., Dunlea, E. J., Huffman, J. A., Onasch, T. B., Alfarra, M. R., Williams, P. I., Bower, K., Kondo, Y., Schneider, J., Drewnick, F., Borrmann, S., Weimer, S., Demerjian, K., Salcedo, D., Cottrell, L., Griffin, R., Takami, A., Miyoshi, T., Hatakeyama, S., Shimono, A., Sun, J. Y., Zhang, Y. M., Dzepina, K., Kimmel, J. R., Sueper, D., Jayne, J. T., Herndon, S. C., Trimborn, A. M., Williams, L. R., Wood, E. C., Middlebrook, A. M., Kolb, C. E., Baltensperger, U., and Worsnop, D. R.: Evolution of Organic Aerosols in the Atmosphere, Science, 326, 1525-1529, 2009.

Kang, E., Root, M. J., Toohey, D. W., and Brune, W. H.: Introducing the concept of Potential Aerosol Mass (PAM), Atmos. Chem. Phys., 7, 5727-5744, doi:10.5194/acp-7-5727-2007, 2007.

Karl, M. Brauers, T., Dorn, H. P., Holland, F., Komenda, M., Poppe, D., Rohrer, F., Rupp, L., Schaub, A., and Wahner, A.: Kinetic Study of the $\mathrm{OH}$-isoprene and $\mathrm{O}_{3}$-isoprene reaction in the atmosphere simulation chamber, SAPHIR, Geophys. Res. Lett., 31, L05117, doi:10.1029/2003GL019189, 2004.

Kirkby, J., Curtius, J., Almeida, J., Dunne, E., Duplissy, J., Ehrhart, S., Franchin, A., Gagne, S., Ickes, L., Kürten, A., Kupc, A., Metzger, A., Riccobono, F., Rondo, L., Schobesberger, S., Tsagkogeorgas, G., Wimmer, D., Amorim, A., Bianchi, F., Breitenlechner, M., David, A., Dommen, J., Downard, A., Ehn, M., Flagan, R. C., Haider, S., Hansel, A., Hauser, A., Jud, W., Junninen, H., Kreissl, F., Kvashin, A., Laaksonen, A., Lehtipalo, K., Lima, J., Lovejoy, E. R., Makhmutov, V., Mathot, S., Mikkilä, J., Minginette, P., Mogo, S., Nieminen, T., Onnela, A., Pereira, P., Petäjä, T., Schnitzhofer, R., Seinfeld, J. H., Sipilä, M., Stozhkov, Y., Stratmann, F., Tome, A., Vanhanen, J., Viisanen, Y., Vrtala, A., Wagner, P. E., Walther, H., Weingartner, E., Wex, H., Winkler, P. M., Carslaw, K. S., Worsnop, D. R., Baltensperger, U., and Kulmala, M.: Role of sulphuric acid, ammonia and galactic cosmic rays in atmospheric aerosol nucleation, Nature, 476, 429-434, 2011.

Korhonen, P., Kulmala, M., Laaksonen, A., Viisanen, Y., McGraw, R., and Seinfeld, J.: Ternary nucleation of $\mathrm{H}_{2} \mathrm{SO}_{4}, \mathrm{NH}_{3}$ and $\mathrm{H}_{2} \mathrm{O}$ in the atmosphere, J. Geophys. Res., 104, 26349-26353, 1999.

Kroll, J. H. and Seinfeld, J. H.: Representation of secondary organic aerosol laboratory chamber data for the interpretation of mechanisms of particle growth, Environ. Sci. Technol., 39, 4159-4165, 2005.

Kulmala, M., Suni, T., Lehtinen, K. E. J., Dal Maso, M., Boy, M., Reissell, A., Rannik, Ü., Aalto, P., Keronen, P., Hakola, H., Bäck, J., Hoffmann, T., Vesala, T., and Hari, P.: A new feedback mechanism linking forests, aerosols, and climate, Atmos. Chem. Phys., 4, 557-562, doi:10.5194/acp-4-557-2004, 2004a.

Kulmala, M., Laakso, L., Lehtinen, K. E. J., Riipinen, I., Dal Maso, M., Anttila, T., Kerminen, V.-M., Hõrrak, U., Vana, M., and Tam- 
met, H.: Initial steps of aerosol growth, Atmos. Chem. Phys., 4, 2553-2560, doi:10.5194/acp-4-2553-2004, 2004b.

Kulmala, M., Vehkamäki, H., Petäjä, T., Dal Maso, M., Lauri, A., Kerminen, V.-M., Birmili, W., and McMurry, P. H.: Formation and growth rates of ultrafine atmospheric particles: a review of observations, J. Aerosol. Sci., 35, 143-176, 2004c.

Kulmala, M., Kontkanen, J., Junninen, H., Lehtipalo, K., Manninen, H. E., Nieminen, T., Petäjä, T., Sipilä, M., Schobesberger, S., Rantala, P., Franchin, A., Jokinen, T., Järvinen, E., Äijälä, M., Kangasluoma, J., Hakala, J., Aalto, P. P., Paasonen, P., Mikkilä, J., Vanhanen, J., Aalto, J., Hakola, H., Makkonen, U., Ruuskanen, T., Mauldin III, R. L., Duplissy, J., Vehkamäki, H., Bäck, J., Kortelainen, A., Riipinen, I., Kurtén, T., Johnston, M. V., Smith, J. N., Ehn, M., Mentel, T. F., Lehtinen, K. E. J., Laaksonen, A., Kerminen, V.-M., and Worsnop, D. R.: Direct observations of atmospheric aerosol nucleation, Science, 339, 943-946, 2013.

Lelieveld, J.: A missing sink for radicals, Nature, 466, 925-926, 2010.

Lelieveld, J., Butler, T. M., Crowley, J. N., Dillon, T. J., Fischer, H., Ganzeveld, L., Harder, H., Lawrence, M. G., Martinez, M., Taraborrelli, D., and Williams, J.: Atmospheric oxidation capacity sustained by a tropical forest, Nature, 452, 737-740, 2008.

Li, Y. J., Chen, Q., Guzman, M. I., Chan, C. K., and Martin, S. T.: Second-generation products contribute substantially to the particle-phase organic material produced by $\beta$-caryophyllene ozonolysis, Atmos. Chem. Phys., 11, 121-132, doi:10.5194/acp11-121-2011, 2011.

Lyubovtseva, Y. S., Sogacheva, L., Dal Maso, M., Bonn, B., Keronen, P., and Kulmala, M.: Seasonal variations of trace gases, meteorological parameters, and formation of aerosols in boreal forests, Boreal Environ. Res., 10, 493-510, 2005.

Merikanto, J., Spracklen, D. V., Mann, G. W., Pickering, S. J., and Carslaw, K. S.: Impact of nucleation on global CCN, Atmos. Chem. Phys., 9, 8601-8616, doi:10.5194/acp-9-8601-2009, 2009.

Neeb, P., Horie, O., and Moortgat, G. K.: The nature of the transitory product in the gas-phase ozonolysis of ethene, Chem. Phys. Lett., 246, 150-156, 1995.

Nölscher, A. C., Williams, J., Sinha, V., Custer, T., Song, W., Johnson, A. M., Axinte, R., Bozem, H., Fischer, H., Pouvesle, N., Phillips, G., Crowley, J. N., Rantala, P., Rinne, J., Kulmala, M., Gonzales, D., Valverde-Canossa, J., Vogel, A., Hoffmann, T., Ouwersloot, H. G., Vilà-Guerau de Arellano, J., and Lelieveld, J.: Summertime total $\mathrm{OH}$ reactivity measurements from boreal forest during HUMPPA-COPEC 2010, Atmos. Chem. Phys., 12, 8257-8270, doi:10.5194/acp-12-8257-2012, 2012.

O'Dowd, C. D. and Hoffmann, T.: Coastal new particle formation: A review of the current stage of the art, Environ. Chem., 2, 245255,2005 .
Pachauri, R. K. and Reisinger, A. (Eds.) : IPCC 4th assessment report: Contribution of Working Groups I, II and III to the Fourth Assessment Report of the Intergovernmental Panel on Climate Change, Cambridge Univ. Press, Cambridge, UK, 2007.

Paulsen, D., Dommen, J., Kalberer, M., Prévôt, A. S. H., Richter, R., Sax, M., Steinbacher, M., Weingartner, E., and Baltensperger, U.: Secondary Organic Aerosol Formation by Irradiation of 1,3,5Trimethylbenzene- $\mathrm{NO}_{\mathrm{x}}-\mathrm{H}_{2} \mathrm{O}$ in a New Reaction Chamber for Atmospheric Chemistry and Physics, Environ. Sci. Technol., 39, 2668-2678, 2005.

Rannik, Ü.: On the surface layer similarity at a complex forest site, J. Geophys. Res., 103, 8685-8697, 1998.

Ryding, M. J., Jonsson, Å. M., Zatula, A. S., Andersson, P. U., and Uggerud, E.: Reactions of $\mathrm{H}^{+}$(pyridine) $)_{m}\left(\mathrm{H}_{2} \mathrm{O}\right)_{n}$ and $\mathrm{H}^{+}\left(\mathrm{NH}_{3}\right)_{1}$ (pyridine $)_{m}\left(\mathrm{H}_{2} \mathrm{O}\right)_{n}$ with $\mathrm{NH}_{3}$ : experiments and kinetic modelling, Atmos. Chem. Phys., 12, 2809-2822, doi:10.5194/acp-12-2809-2012, 2012.

Seinfeld, J. H. and Pandis, S. N.: Atmospheric chemistry and physics: From air pollution to climate change, 2nd Edn. Wiley Interscience, New York, 2006.

Slowik, J. G., Wong, J. P. S., and Abbatt, J. P. D.: Real-time, controlled $\mathrm{OH}$-initiated oxidation of biogenic secondary organic aerosol, Atmos. Chem. Phys., 12, 9775-9790, doi:10.5194/acp12-9775-2012, 2012.

Solomon, S., Qin, D., Manning, M., Chen, Z., Marquis, M., Averyt, K. B., Tignor, M., and Miller, H. L. (Eds.): Contribution of Working Group I to the Fourth Assessment Report of the Intergovernmental Panel on Climate Change, Cambridge University Press, Cambridge, UK, 2007.

Spracklen, D. V., Carslaw, K. S., Merikanto, J., Mann, G. W., Reddington, C. L., Pickering, S., Ogren, J. A., Andrews, E., Baltensperger, U., Weingartner, E., Boy, M., Kulmala, M., Laakso, L., Lihavainen, H., Kivekäs, N., Komppula, M., Mihalopoulos, N., Kouvarakis, G., Jennings, S. G., O’Dowd, C., Birmili, W., Wiedensohler, A., Weller, R., Gras, J., Laj, P., Sellegri, K., Bonn, B., Krejci, R., Laaksonen, A., Hamed, A., Minikin, A., Harrison, R. M., Talbot, R., and Sun, J.: Explaining global surface aerosol number concentrations in terms of primary emissions and particle formation, Atmos. Chem. Phys., 10, 4775-4793, doi:10.5194/acp-10-4775-2010, 2010.

Sun, T. S.: Construction, Online-Untersuchung und Modellierung von Parametern zur Beschreibung atmosphärischer Nukleation durch Simulationskammerstudien (COMPASS), Master thesis, Goethe University, Frankfurt/Main, 2013.

Wang, J., Doussin, J. F., Perrier, S., Perraudin, E., Katrib, Y., Pangui, E., and Picquet-Varrault, B.: Design of a new multi-phase experimental simulation chamber for atmospheric photosmog, aerosol and cloud chemistry research, Atmos. Meas. Tech., 4, 2465-2494, doi:10.5194/amt-4-2465-2011, 2011. 